\title{
Sepiolite and sepiolite-bound humic acid interactions in alkaline media and the mechanism of the formation of sepiolite-humic acid complexes
}

\author{
Eyüp Sabah, ${ }^{*}$ Sabeha Ouki \\ ${ }^{1}$ Department of Mining Engineering, Faculty, Faculty of Engineering, Afyon Kocatepe University, 03200 \\ Afyonkarahisar, Turkey \\ ${ }^{2}$ Department of Civil and Environmental Engineering, Faculty of Engineering and Physical Sciences, University \\ of Surrey, Guildford, United Kingdom
}

\begin{abstract}
The surface-controlled reactions and interfaces of clays and/or clay minerals are strongly determined by the adsorption of dissolved humic substances which have surface active characters. Consequently, this may lead to an improved understanding of organo-clay complexes for remediation purposes of polluted areas. The interactions between sepiolite and sepiolite-bound humic acid (HA), and its influence on the mechanism of the formation of sepiolite-humic acid complexes were examined by characterizing the structure of sepiolite through UV/Vis spectroscopy, field emission scanning electron microscopy (SEM+FEG), specific surface area, pore size and volume, and Fourier transform infrared spectroscopy (FTIR). The UV-VIS spectral results of the raw sepiolite showed that there is no correlation between $\mathrm{UV}_{254}$ and the amount of humic substance released from sepiolite is dependent on increasing extraction time. The low values of humification index of the sepiolite confirmed the presence of HA with higher, and similar molecular weight, particle size, humification degree and aromaticy. Hence, it can be concluded that HA groups are presumably associated with the large quantity of silanol groups located on the sepiolite external surface preferentially through $\mathrm{H}$-bonds and/or surface complexation interactions between the functional groups in HA and dissolved metal cations $\left(\mathrm{M}^{\mathrm{n}+}\right)$. This finding is in good agreement with results from FTIR and SEM-FEG investigations. EDAX analysis of the HA-extracted sepiolite illustrated a strong decrease in $\mathrm{Mg}^{2+}, \mathrm{Ca}^{2+}$ and $\mathrm{K}^{+}$content indicating that electrically charged sites on HA may form metal complexes of high stability through chelation.
\end{abstract}

Keywords: Sepiolite; sepiolite-bound humic; humic acid complexes; extraction; mechanism

*Corresponding author.

E-mail address: esabah@aku.edu.tr (E. Sabah) 


\section{Introduction}

Humic materials are the most widely-spread natural complexing ligands occurring in nature. One of the main functions of dissolved humic materials in the environment is to remove toxic metals, anthropogenic organic chemicals, hydrophobic (including PAHs) and other pollutants from water (Peña-Méndez et al., 2005; Shin et al. 1999; Radian and Mishael, 2012). The higher solubility and mobility of the pollutants in the presence of dissolved humic materials due to their ability to reduce surface tension of water, result in their binding to dissolved humic materials. This can not only affect their transport and aqueous concentration but it can also influence their chemical degradation, photolysis, volatilization, toxicity, and bioavailability (Chiou et al. 1986; Spitzy and Leenheer, 1991; Rav-Acha, and Rebhun, 1992; Kordel et al. 1997; Frimmel, 1998; Laor et al., 1998; Frimmel and Christman, 1998; Frimmel et al., 2002). It has also been known that dissolved humic substances, such as humic acid (HA, insoluble at acidic $\mathrm{pH}$ ) and fulvic acid (FA, water soluble at acidic to alkaline $\mathrm{pH}$ ), are complex and heterogeneous mixtures of polydispersed materials, negatively charged due to the presence various chemically reactive functional groups, including carboxylic $(-\mathrm{COOH})$ and phenolic $-\mathrm{OH}$ groups on aromatic and aliphatic chain, with $\mathrm{pH}$-dependent properties ( $\mathrm{Gu}$ et al., 1994; Vermeer et al., 1998; Vermeer and Koopal, 1998; Chen et al., 2007). FA has a higher amount of carboxylic and phenolic groups (higher molar mass), contains more carbon, and is less soluble compared to HA, which consists of a more aromatic structure Stevenson, 1994). The major reason for the importance of FA and HA in soil/clay chemistry, sediment biogeochemistry and environmental reactivity is the presence and position of the functional groups (particularly carboxyl and phenolic hydroxyl groups), which make FA and HA effective in cation exchange and complexation reactions (Tan, 1986; Simpson et al., 2006).

Among the inorganic substances that constitute the soils, clays and metal oxide minerals are the most abundant, and their surface-controlled reactions and interfaces are strongly determined by the adsorption of dissolved humic substances which have surface active characters. As a consequence, this characteristic could improve the understanding of organoclay complexes for the purpose of contaminated soil remediation. Some of the dominants factors influencing the nature of complexation between dissolved humic substances and clays are $(i)$ the nature of the clay mineral (surface chemistry, specific surface area, pores), (ii) environmental conditions such as $\mathrm{pH}$, ionic strength, composition of cations, anions, etc., and (iii) the nature the dissolved humic substances that are often interdependent (Theng, 2012). Researchers have extensively investigated the influence of the change in solution conditions (e.g. nature of exchangeable cations, medium $\mathrm{pH}$ and ionic strength, molecular weight of humic substances) on dissolved humic substances (FA/HA) adsorption on clay mineral surfaces (Mortland, 1970; Greenland, 1971; Baham and Sposito, 1994; Schlautman and Morgan, 1994; Arnarson and Keil, 2000; Satterberg et al., 2003; Feng et al., 2005). It is apparent that while the process of selective adsorption of dissolved humic substances onto clay surfaces is generally accepted, there is considerable variation due to the heterogeneities and complexity of humic substances in their composition and conformation that are reported to be preferentially sorbed (Nayak et al., 1990; Murphy et al., 1994; Collins et al., 1995; Vermeer and Koopal, 1998; Vermeer et al., 1998; Namjesnik-Dejanovic et al., 2000; Khalaf et al., 2003; Wang and Xing, 2005; Feng et al., 2006; Chilom and Rice, 2009). Furthermore, 
adsorption of FA/HA on minerals is dependent on clay-polyvalent ion like $\mathrm{Ca}^{2+}, \mathrm{Mg}^{2+}, \mathrm{Fe}^{3+}$, $\mathrm{Al}^{3+}$, and on the surface properties of the mineral (Varadachari et al., 1991; Varadachari et al., 1994; Varadachari et al., 1995; Kretzschmar et al., 1997; Tombácz et al., 1998; Furukawa, 2000; Specht et al. 2000; Chorover and Amistadi, 2001; Księżopolska, 2001; Balcke et al., 2002; Kaiser and Guggenberger, 2003; Feng et al., 2005; Majzik and Tombácz, 2007; Martinez et al., 2010; Ksiezopolska and Pazus, 2011; Zhang et al., 2012; Ding et al., 2013). As a result, the differences in type of clay minerals would lead to different combinations of adsorption mechanisms (Evans and Russell, 1959; Werhaw, 1986; Theng and Tate, 1989; Wershaw and Pinckney, 1989; Zhou et al., 1994; Ohashi and Nakazawa, 1996; Wattel-Koekkoek et al., 2001; Wattel-Koekkoek, 2002; Saada et al., 2003; Tombácz et al, 2004; Majzik and Tombácz, 2007; Sposito, 2008). Most of these studies have focused on the interaction between dissolved humic substances and the crystalline clay minerals such as kaolinite (typical two-sheet phyllosilicates), vermiculite (the expanding three-sheet phyllosilicates), smectite (strongly expanding three-sheet phyllosilicates), chlorites (foursheet silicates). These are bound to the soils but also to the layer-fibrous structure clay minerals such as the palygorskite and sepiolite including dissolved humic substances. However very little work has been published regarding their relevance to many aspects of surface and environmental chemistry. An attempt was made by Benli (2014) to present the effects of humic acid release from sepiolite on its interfacial and rheological properties of alkaline dispersions. The results observed that highly alkaline $\mathrm{pH}$ caused an increase in the total amounts of HA and free ions in relation to the formation/precipitation of both hydrophobic HA aggregate and HA- $\mathrm{Mg}^{2+}$ complexes which have a spherical shape in the size range of $18-63 \pm 8 \mathrm{~nm}$ at $\mathrm{pH} 11.5$. Based on these findings, alkaline environment also results in significant changes in the surface properties of sepiolite from the anisotropic to the higher hydrophobic level like natural hydrophobic minerals, e.g. talc. In an early technical note (Singer and Huang, 1989) it was shown that the effect of $\mathrm{pH}$ and heat activation on the adsorption behavior of humic acid was obtained from a typical Cryoboralf on the sepiolite used from Vallecas and the palygorskite from Florida. Humate adsorption on both palygorskite and sepiolite at $\mathrm{pH} 6.5$ was found to increase with increased initial humate concentration, and decrease with preheating the clay samples and then considerably dispersing in the humate solutions. Golden et al. (1985) also investigated the instability of palygorskite and sepiolite taken from the same region under slightly alkaline conditions (0-8 mmole $\mathrm{NaOH}$ ) to determine the transformation of palygorskite and sepiolite to smectite under laboratory conditions. In a similar manner, the study about the behaviour and stability of the Vallecas sepiolite in aqueous solutions of neutral and weak alkaline $(0.04 \mathrm{~N} \mathrm{NaOH})$ conditions at room temperature have been conducted by Martinez-Ramirez et al. (1996) Collectively, these two studies indicate that palygorskite treatment for 24 days in these media yielded a smectite, and that after 24-28 days in similar conditions, the sepiolite is destroyed gradually, e.g. produced small surface structural changes. Currently, there is no published research on the structural and functional characterization of sepiolite-complexed dissolved organic matter and the corresponding interaction mechanisms of humic substances with sepiolite surfaces in order to better understand the adsorption and colloidal-rheological environmental applications of sepiolite. 
The clay minerals palygorskite and sepiolite occur in many arid and semi-arid soils (Kadir et al., 2002). They are both fibrous in form, a characteristic dictated by their chain-type (linear) structure and are predominantly silico-magnesian containing varying amounts of $\mathrm{Al}^{3+}, \mathrm{K}^{+}, \mathrm{Ca}^{2+}, \mathrm{Fe}^{2+}, \mathrm{Fe}^{3+}$ ions. They contain hydroxyls, zeolitic and bound water. Sepiolite and organo sepiolite have a significant potential as alternative adsorbents. This is due to their inherent strong sorption and complexation ability (mainly due to their high surface area, to their structural channels running parallel to the fibre length, and to their pores) toward various environmental pollutants of concern. This coupled with their environmental compatibility and cost effectiveness makes them ideal alternative adsorption materials for a wide range of industrial and pharmaceutical wastewater treatment applications.

The purpose of the present study is to develop an understanding of the interactions between sepiolite and humic acid bound to sepiolite, and their impact on the mechanism of sepiolite-humic acid complexes formation with a view to optimize the adsorption capability of the system. Two different approaches have been used to study the sepiolite-complexed organic matter. One involves the gradual removal by extraction of the humus substances from the sepiolite and replacing it by humic acid and the other is to understand the relations between surface complexation, and their nature in the sepiolite-organic matter system.

\section{Materials and methods}

\subsection{Materials}

Sepiolite used in the experiments are natural, non-swelling fibrous clay from SivrihisarKurtşeyh occurring at the upper Sakarya Section of Central Anatolian Neogene Basins southeast of Eskisehir, Turkey.

Inorganic chemicals such as $\mathrm{HCl}$ and $\mathrm{NaOH}$ used for adjusting $\mathrm{pH}$ and zeta potential measurements were obtained from Fisher Scientific, and all solutions were prepared using deionized water with a conductivity of $0.067 \mu \mathrm{s} / \mathrm{cm}$.

\subsection{Methods}

Raw sepiolite was comminuted by two stage crushing in laboratory jaw and roll crusher to prepare samples less than $2 \mathrm{~mm}$ as a starting material, and it was then dry ground in a vibrating ball mill for short grinding time at $25 \mathrm{~min}$ to avoid the structural deformation (Vučelić et al., 2002; Kojdecki et al., 2005). Particle size distribution of ground samples was analyzed by a technique based on laser light scattering using MALVERN Mastersizer 2000.

The density of both sepiolite samples was measured using a Quanta- chrome Ultrapycnometer 1000, and bulk density was measured with Haver bulk density tester according to EN 1097-3 standard (1998). The BET surface area, pore volume and average pore diameter of sepiolites before and after extraction experiments were determined using the Qantachrome instrument using nitrogen gas adsorption at $-196^{\circ} \mathrm{C}$. Before each measurement all samples were outgassed for $10 \mathrm{~h}$ by heating $50^{\circ} \mathrm{C}$ (Sarıkaya, 1981) under vacuum.

Chemical analysis of the sepiolite was determined with an X-ray fluorescence (XRF) spectrometer (Rigaku ZSX Primus II XRF). X-ray powder diffraction patterns (XRD) of the 
tested sepiolite samples were measured by Panalytical X Pert Pro MPD. Total organic carbon (TOC) measurement of the original sepiolite samples was carried out at Istanbul Technical University EMCOL Labs in Turkey. A JEOL JSM-7100F field emission scanning electron microscope (SEM-FEG) equipped with a Link System energy dispersive X-ray (EDX) microanalyser was used to observe the textural features of natural and humic acid extracted sepiolite. Fourier transform infrared spectra (FTIR) were recorded on the Agilent Cary 640 FTIR high performance spectrometer using attenuated total reflectance (ATR) and diffuse reflection (DR) for rapid characterization of sepiolite samples. The spectra were measured in the range from 4000 to $400 \mathrm{~cm}^{-1}$ (32 scans, $4 \mathrm{~cm}^{-1}$ resolutions).

The zeta potentials of sepiolite samples were determined at $23 \pm 5^{\circ} \mathrm{C}$ by Zetasizer Nano $\mathrm{Z}$ (Malvern Instruments) which uses micro-electrophoresis/electrophoretic light scattering technology. Zeta potential measurements were carried out as a function of the $\mathrm{pH}$ of natural sepiolite suspensions. In this procedure, the sepiolite suspensions with a minimum solid concentration of $0.1 \mathrm{~g} / \mathrm{l}$ to avoid particle interaction $\left(10^{-2} \%\right.$ mass according to Malvern's recommendation) were conditioned at $500 \mathrm{rpm}$. The $\mathrm{pH}$ value of each suspension was adjusted by adding either $\mathrm{NaOH}$ or $\mathrm{HCl}$. The $\mathrm{pH}$ of the solution was measured using the combination HI 1131 pH electrode with $\mathrm{Ag} / \mathrm{AgCl}$ reference cell (HI $2210 \mathrm{pH}$ meter, Hanna Instruments). After conditioning for $10 \mathrm{~min}$ followed by centrifuging for another $10 \mathrm{~min}$ at $3000 \mathrm{rpm}$ an aliquot was taken from the supernatant and used to measure the zeta potential. The average of ten measurements was taken to represent the measured potential. The mean relative standard deviation $(\sigma)$ of the values reported usually did not exceed 5 .

To separate organic matter from the inorganic, humic acid was isolated from air dried sepiolite according to the procedure recommended by the International Humic Substances Society (Swift, 1996). Briefly, $10 \mathrm{~g}$ of airdry sepiolite were mixed vigorously on a stir plate (300 rpm) under $\mathrm{N}_{2}$ in $100 \mathrm{ml}$ of $0.1 \mathrm{M} \mathrm{NaOH}$ for different times (max. $4 \mathrm{~h}$ ) at room temperature. Conducting extraction under $\mathrm{N}_{2}$ is necessary to avoid redox processes, to which quinone and phenol systems and their derivatives present in the aromatic core of humic acid particles are highly sensitive (Ksiezopolska and Pazus, 2011). The alkaline solution was separated from the residue by centrifugation $(11,000 \mathrm{rpm}$ for $20 \mathrm{~min})$. At the end of this time the supernatant was filtered through $0.45 \mu \mathrm{m}$ syringe membrane filter (Millipore), and the concentration of humic acid remaining in the aqueous phase was measured immediately to avoid the ageing effect occurred in the presence of oxygen according to Pokorna et al. (2001) by double beam UV-visible spectrophotometer (Biochrom Libra S60) at 250, 254, 265, 350, $365,400,450,465,550,600,665,700 \mathrm{~nm}$ wavelengths using $10 \mathrm{~mm}$ path length quartz cell. Since humic substances usually yield uncharacteristic spectra in the UV-visible, these data were used for the determination of the $\mathrm{E}_{4} / \mathrm{E}_{6}$ (absorbances at $465 \mathrm{~nm}$ and $665 \mathrm{~nm}$ ), the $\mathrm{E}_{2} / \mathrm{E}_{3}$ ratio (absorbances at $250 \mathrm{~nm}$ and $365 \mathrm{~nm}$ ), the absorptivity $\varepsilon_{272}$ (absorbance at $272 \mathrm{~nm}$ ) and the band half-width of the electronic transition absorbance bands $\Delta_{\mathrm{ET}}$ (absorbance at 280 and 350). All these data give information about changes in aromaticity, hydrophobic content, biodegradability, and functionality of humic substances (Pokorna et al., 2001; Beznosikov and Lodygin, 2009) and whether certain fractions of the humic substance are isolated preferentially from the sepiolite. Total organic carbon (TOC) measurement of the liquid samples was performed by accredited testing laboratory of Thames Water Utilities Ltd. in the UK. A Perkin-Elmer Optima 5300DV inductively coupled plasma optical emission 
spectrometry (ICP-OES) was used to analyse for the metal ion $\mathrm{Mg}^{2+}$ in the supernatant. Considering the alkaline nature of the supernatant, a drop of ICP quality nitric acid from Fluca ( $\geq 69 \%$ ) was added to the supernatant before analysis so as to avoid hydrolysis and/or precipitation of the metal ions. The alkaline modified sepiolite samples were washed 12-14 times with deionized water to remove any unbound organics, re-centrifuged and decanted until their $\mathrm{pH}$ reached to the initial $\mathrm{pH}$. Finally, they were dried at $50^{\circ} \mathrm{C}$ overnight and analyzed for the FTIR, SEM, and zeta potential.

\section{Results}

\subsection{Sepiolite characterization}

The chemical and physical characteristics of raw sepiolite are shown in Tables 1. Sepiolite used in this study is very low in aluminum and iron Sepiolite, ground to $\leq 120.2 \mu \mathrm{m}$, produced an average particle size $\left(\mathrm{d}_{50}\right)$ of $19.2 \mu \mathrm{m}$, whereas its density and bulk density were $2.33 \mathrm{~g} / \mathrm{cm}^{3}$ and $304.2 \mathrm{~g} / \mathrm{L}$, respectively. Organic matter is also present in almost every sepiolite sample. The total organic and inorganic carbon ratios of raw sepiolite were $1.21 \%$ and 1.43 , respectively (Table 1 ).

The X-ray diffraction (XRD) pattern belonging to raw sepiolite is given in Figure 1. The sample mineralogical composition showed clearly that the major component was sepiolite, followed by dolomite which its presence was confirmed through the bands at $1427 \mathrm{~cm}^{-1}$ and $728 \mathrm{~cm}^{-1}$ in the FTIR spectra of raw sepiolite (Eren et al., 2010; Lescano et al., 2014). From the diffractogram of sepiolite, the presence of peaks distinctive for sepiolite and dolomite are obvious, indicating poor crystallinity. Moreover, the FTIR spectrum of raw sepiolite (Figure 2) ranges from very to intermediately crystalline sepiolite due to the absence of the band at $3720 \mathrm{~cm}^{-1}$ assigned to the $\mathrm{OH}$ stretching vibration of the silanol (Si-OH) groups. The 3640 $\mathrm{cm}^{-1}$ band was suggested to arise from limited trioctahedral substitutions, the $3620 \mathrm{~cm}^{-1}$ band from structural $\mathrm{MgOH}$ dioctahedral stretching modes and by the presence of the very small band of the triple bridge group $\mathrm{Mg}_{3} \mathrm{OH}$ in the octahedral sheet at $3685 \mathrm{~cm}^{-1}$, attributed to structural hydroxyls (Martienssen, 2009). Based on the analysis of FTIR spectra as well as XRD data (Figure 1) and the relatively high $\mathrm{CaO}$ content $6.01 \%$ in Table 1, the sepiolite sample studied is shown to consist mainly of a mclay fraction and impurities such as organic matter and dolomite generally accepted as representing a moderate quality.

The structure and morphology of sepiolite determines the presence of a large number of terminal silica tetrahedra on the ribbon at the external surfaces (Serratosa, 1979). Silanol groups are formed as a result of broken Si-O-Si bonds at external surfaces, balancing their residual charge by accepting either a proton or a hydroxyl group to form $\mathrm{Si}-\mathrm{OH}$ groups which are capable of reacting with certain organic substances by formation of different bondings and by modifying the structure and surface of the sepiolite. The abundance of $\mathrm{Si}-\mathrm{OH}$ groups in sepiolite determined using FTIR are shown in Figure 2. The bands in the $1200-400 \mathrm{~cm}^{-1}$ range represent the lattice vibrations of sepiolite. The bands of $\mathrm{Si}-\mathrm{O}$ combination stretch at 1209, 1010, and $975 \mathrm{~cm}^{-1}$ form as a result of the $\mathrm{Si}-\mathrm{O}$ vibrations (Sevim et al., 2011). The bands at 495 and $508 \mathrm{~cm}^{-1}$ can be attributed to an $\mathrm{O}-\mathrm{Si}-\mathrm{O}$ bending, while that at 616 and 650 $\mathrm{cm}^{-1}$ results from an $\mathrm{Mg}-\mathrm{OH}$ bending mode vibrations. The $\mathrm{C}-\mathrm{O}$ stretching vibrations 
obtained at 1456 and $881 \mathrm{~cm}^{-1}$ are the characteristics of carbonate, which is in agreement with the results of chemical analysis and XRD patterns. A band of the triple bridge group $\mathrm{Mg}_{3} \mathrm{OH}$ at $3686 \mathrm{~cm}^{-1}$ is a characteristic IR spectra of sepiolite attributed to structural hydroxyls. On the other hand, the bands recorded at $3560 \mathrm{~cm}^{-1}$ and $3238 \mathrm{~cm}^{-1}$ are respectively assigned to the $\mathrm{OH}$ stretching, representing the zeolitic water in the channels and bound water coordinated to magnesium in the octahedral sheet. The $\mathrm{OH}$-bending mode at $1656 \mathrm{~cm}^{-1}$ is also due to the $-\mathrm{OH}$ bending vibrations of zeolitic water (Frost et al., 2001).

The nitrogen adsorption/desorption isotherm at $-196^{\circ} \mathrm{C}$ and cumulative pore volume coupled with log-differential pore volume distribution curves are shown in Figure 3 . The adsorption isotherm of natural sepiolite is of the type II according to The International Union of Pure and Applied Chemistry (IUPAC) classification and appears in the shape of a hysteresis to a certain degree (Broekhoff, 1979; Sing et al., 1985; Shields et al., 2004; Alothman, 2012). The visual inspection of isotherm shapes indicates that the porous network of the sepiolite sample presents micropores along with mesopores and macropores. The total amount of nitrogen adsorbed at high relative pressure is 55\%. This result indicates higher porosity, yielding a greater available volume for nitrogen adsorption. The saturation plateau is not parallel to the relative pressure axis, indicating that the sepiolite contain a large portion of mesopores. This is confirmed by the cumulative pore volume and log-differential pore volume distribution curves shown in Figure 4. The natural sepiolite has a BET surface area of $358 \mathrm{~m}^{2} / \mathrm{g}$, a pore diameter between $7.26 \sim 251.16 \AA$, and its pore volume with pore diameter of $7.26 \sim 19.69 \AA$ is about $13.44 \%$. Moreover, a very sharp peak at pore half-width around $8 \AA$ obtained from the log-differential pore volume distribution curve spanning the interval 7-251 $\AA$ (Figure 4), related to the entrance of $\mathrm{N}_{2}$ inside the intracrystalline tunnels, is an indication of uniform micropores and multimodal pore size distribution in the sepiolite. The average pore diameter related to micro-mesopores, determined from specific micro-mesopore volume and specific surface area, was about $47.2 \AA$.

The textural features observed by field emission scanning electron microscopy (SEMFEG) confirm that the natural sepiolite studied present a characteristic fibrous morphology (length, width, fibre curliness, fibre arrangement, and porosity) as illustrated in Figure 5. The fibres are composed of tablets and needle-like structures arranged in parallel (Suárez and García-Romero, 2012), and consist of intermediates between 1 and $10 \mu \mathrm{m}$ of length that are much longer than their widths. Semi-quantitative EDX analysis has shown that natural sepiolite is composed mainly of $\mathrm{Si}$ and $\mathrm{Mg}$ and smaller amounts of $\mathrm{Ca}$ and $\mathrm{Al}$.

Electrokinetic surface-charge measurements have long been recognized as extremely useful tools for the interfacial characterization of colloidal systems. These measurements are increasingly successful in characterising solid surfaces. Sepiolite has negatively charged sites on its planar surface, and the amphoteric surface hydroxyl groups ( $\mathrm{Si}-\mathrm{OH}$ ) located onto the channel sides. Certain isomorphic substitutions in the tetrahedral or octahedral sheets, such as $\mathrm{Al}^{3+}$ instead of $\mathrm{Si}^{4+}$ (Shuali et al., 2011) or $\mathrm{Mg}^{2+}$ by $\mathrm{Al}^{3+}$ (Ruiz-Hitzky, 2011), are responsible for the exchangeable cations that are needed to compensate for the electrical charge and constitute the charged adsorption sites ( $\mathrm{P}$ sites), similar to smectites and other layered charged silicates. The silanol groups at external surfaces of sepiolite can be protonated and deprotonated under acid and alkaline $\mathrm{pH}$ conditions, respectively. At the point of zero charge 
(p.z.c.), the surface is essentially uncharged, while at $\mathrm{pH}$ values above and below the p.z.c, it will be negatively and positively charged, respectively.

The zeta potential profiles of raw sepiolite given in Figure 6 as a function of suspension $\mathrm{pH}$ measured over the range 2-10 indicates that the changes of the zeta potential curves for raw sepiolite follow the trend from positive to negative with increasing $\mathrm{pH}$. Positive zeta potentials are observed for the sepiolite sample in strong acidic solutions $(\mathrm{pH} \leq 3.22)$. Raw sepiolite carry an apparent negative zeta potential in the majority of the tested $\mathrm{pH}$ range; its p.z.c value was 3.22, which is comparable to published data (Çelik, 2004; Sabah et al., 2007; Chen et al., 2012). The resulting zeta potential was $-15.8 \pm 3.87 \mathrm{mV}$ for raw sepiolite at $\mathrm{pH}=7.26$ which was the natural $\mathrm{pH}$ of suspension. It is widely recognized (Frenkel et al., 1992; Tarchitzky et al., 1993; Vdović, 2001) that the negative zeta potential of mineral particles in natural environments is usually the result of the organic matter such as dissolved humic substances present in the clays. Acting as a coating and/or incorporated in the structure, dissolved organic matter renders the surface charge of particles uniformly negative regardless of their composition and various functional groups attached to aliphatic-aromatic backbone structure which are highly sensitive to different chemical conditions of solution. Kretzschmar et al. (1997) have reported that sorption of humic acid to kaolinite should therefore continuously shift the electrophoretic mobility of the clay particle to more negative values, and contributes towards the lowering of p.z.c of kaolinite from 4.8 to 2.0.

\subsection{Characterization of sepiolite-bound humic acid (HA)}

HAs generally show strong absorbance in the UV-Vis range (from 190 to $800 \mathrm{~nm}$ ), particularly in the UV region, because of the presence of aromatic chromophores and/or other organic compounds Accordingly, the UV-Vis spectra of the three natural organic matter fractions showed a generally decreased absorptivity (or optical density) as the wavelength increased (Chen et al., 2002; Nadi, 2012). Since HAs usually yield uncharacteristic spectra in the UV-visible, soil scientists have used the ratio of optical densities or absorbance of their dilute, aqueous solutions at 465 and $665 \mathrm{~nm}\left(\mathrm{E}_{4} / \mathrm{E}_{6}\right)$ for characterization purposes of HAs. Higher molecular weight and higher degree of condensation of the aromatic rings will be indicated by lower $E_{4} / E_{6}$ ratio value. Humic acids have a lower $E_{4} / E_{6}$ ratio, more humification or ageing. This ratio is independent of the concentration of the HA but is characteristic of different natural organic matter fractions or HAs obtained from different sources. A low $\mathrm{E}_{4} / \mathrm{E}_{6}$ or $\mathrm{E}_{2} / \mathrm{E}_{3}$ ratio for soil $\mathrm{HA}$ may be largely attributed to the absorption by aromatic $\mathrm{C}=\mathrm{C}$ functional groups (Pokorná et al., 2001; McDonald et al., 2004; Helms et al., 2008; Yang and Xing, 2009).

Classical parameters such as the absorbance ratio $\mathrm{E}_{4} / \mathrm{E}_{6}$ and the $\Delta \log \mathrm{K}$ coefficient, the so called index of humification degree, correlates also with the average molecular weight and size of humic substances (Chen et al., 1977; Giovanela et al., 2010). Though, other ratios like $\mathrm{E}_{350} / \mathrm{E}_{450}$ or $\mathrm{E}_{350} / \mathrm{E}_{550}$ or $\mathrm{E}_{250} / \mathrm{E}_{365}$ can be used with the same purpose (Burba et al., 1995; Enev et al., 2014). In the present study, the variation range of the absorbance ratios $E_{4} / E_{6}$ from 20 to $240 \mathrm{~min}$, of the extracted humic substances, are given in Table 2. As can be observed, the values for the $\mathrm{E}_{4} / \mathrm{E}_{6}$ ratio of humic substances extracted from the raw sepiolite were low and changed in a narrow range (3.19-3.28) during the increasing extraction time. Kononova 
(1982) suggests values of the relationship $\mathrm{E}_{4} / \mathrm{E}_{6}$ for humic acid smaller than 5.0 and between 6.0 and 8.0 for fulvic acids (Cunha et al., 2009).

\section{Discussion}

The results obtained intend to shed some light on the interactions between sepiolite and humic acid bound to sepiolite, and its influence on the mechanism of the formation of sepiolite-HS complexes. Two basically different approaches have been used to study the sepiolite-complexed organic matter. One involves the gradual removal of the HAs from the sepiolite, and comparative investigation of the residual samples; and the other is to study the relations between surface complexation, and surface charge modification in sepiolite-organic matter system.

As expected, and in agreement with previously published data (Österberg et al., 1987; Giovanela et al., 2010), in all the spectra obtained in the UV-Vis region are typical of HAs and followed the featureless, monotonic increase in intensity almost consistently from 700 to $250 \mathrm{~nm}$ (Figure 7). However, little structural information can be gathered from such spectra, but through examination of the values of the different indexes $\left(\mathrm{E}_{465} / \mathrm{E}_{665}, \log \mathrm{E}_{400}-\log \mathrm{E}_{600}\right.$, and $\mathrm{E}_{450}-\mathrm{E}_{700}$ ) calculated from the UV-Vis spectra, some qualitative estimations about the HAs can be made.

Summers et al. (1987) and Nadi (2012) also reported a strong correlation between UV absorbance at $254 \mathrm{~nm}\left(\mathrm{UV}_{254}\right)$ and dissolved organic carbon (DOC). In contrast, there was not a correlation between $\mathrm{UV}_{254}$ and the amount of organic carbon released from sepiolite depending on increased extraction time. This was confirmed by the subtraction $\mathrm{E}_{450}-\mathrm{E}_{700}$ which expresses the relative amount of extracted HA (Dick and Burbab, 1999), as a function of time, indicating that HA extraction reached its maximum within the first $20 \mathrm{~min}$ and then no significant change was observed thereafter (Table 2).

The values obtained for the $\mathrm{E}_{4} / \mathrm{E}_{6}$ ratios were around 3.0 for the humic acid of the raw sepiolite. As a consequence, the low values of humification index of the raw sepiolite confirmed the presence of HA with higher, and similar molecular weight, particle size, humification degree and aromaticy. The similarity of the $\Delta \log \mathrm{K}$ values used as indexes for the degree of humification of HA extracted from the raw sepiolite are in agreement with the results deduced from the above. Based on these findings, no structural modification of HA was observed during this extraction period. In addition, the $\Delta \operatorname{logK}$ can also be used to classify the humic acid, in general, which can be grouped into four major types: A, B, $\mathrm{R}_{\mathrm{p}}$, and P types. In our case (Table 2), all samples obtained from different extraction time were classified as humic acid of type B according to Kumada (1988).

In general, it appears that several bonding mechanism may be operating in the formation of clay-humus complexes. However, the relative contributions of the various mechanisms are not clear. Moreover, the predominant bonding mechanisms are likely to differ for different clay minerals. For instance, raw sepiolite contains the lowest proportion of the total organic carbon (TOC), as seen as from Table 1 and Figure 8, much of which is humic acid whose direct bonding to exposed crystal and/or the octahedra at the edges of sepiolite is not significant. Considering the rapid extraction of humic acid with $0.1 M \mathrm{NaOH}$ in the first 20 min and the little amount of released humic acid, change depends on the increasing extraction 
time, and no detectable structural alteration of sepiolite occurred in the absence of humic substance (Figure 8-a). It can be concluded that humic acid containing many functional groups was presumably associated with the large quantity of silanol groups (in contrast to other clay mineral groups, such as smectites and vermiculites). These are located on the external surface at the edges of the structural channels of sepiolite preferentially through $\mathrm{H}$ bonds and/or surface complexation interactions between the functional groups in humic acid and dissolved metal cations $\left(\mathrm{M}^{\mathrm{n}+}\right)$. It has been deduced that the binding of humic acid is controlled by i) the sepiolite surface active groups on the external surfaces in the form of surface-bonded HAs, and ii) the mono-, di-, and multivalent cations like $\mathrm{K}, \mathrm{Ca}^{2+}, \mathrm{Mg}^{2+}$ and $\mathrm{Al}^{3+}$ and their potential factors which determine the relative complex-promoting abilities of the cation, which are in good agreement with results of SEM investigations (Figure 10).

In the alkaline extraction, the $\mathrm{pH}$-dependent charge of the mineral surface as well of the $\mathrm{HS}$, is converted to its negative form, and HS solubilization occurs due to repulsion between equally negative charged surfaces and formation of soluble HS salts. By this extraction, mainly $\mathrm{H}$-bonding and surface complexation interactions between $\mathrm{HS}$ and mineral surfaces are broken up (Stevenson, 1994).

Figure 9 shows the FTIR spectra of the raw sepiolite and the samples before and after extraction in $0.1 \mathrm{M} \mathrm{NaOH}$ solution for $20,60,120$ and $240 \mathrm{~min}$. The main features of the sepiolite spectral data ranging from 4000 to $3500 \mathrm{~cm}^{-1}$, indicate main vibrational frequencies at 3686 and $3560 \mathrm{~cm}^{-1}$ corresponding to $\mathrm{Mg}-\mathrm{OH}$ group and bound water cooridinated to magnesium in the octahedral sheet, respectively. The band characteristic of $\mathrm{OH}$ stretching from coordinated water that appears at $3560 \mathrm{~cm}^{-1}$, resulted in a broadening but its frequeny did not change significantly even at increasing extraction times. On the other hand, treatment with inreasing extraction time gradually diminished the intensity of the vibration bands of the $\mathrm{OH}^{-}$groups corresponding to the coordination of water molecules that vibrate at $3685 \mathrm{~cm}^{-1}$. These are placed in the most external part of the sepiolite and joined to the changes in sepiolite surface, indicating that small changes are being produced on the external clay structure. Special attention should be given to bands located at $3720 \mathrm{~cm}^{-1}$ which is assigned to the $\mathrm{OH}$ stretching vibrations of silanol groups $(\mathrm{Si}-\mathrm{OH})$ located at the external surface of the silicates. Perturbations in the $\mathrm{OH}$ stretching vibrations of the silanol groups is often used to prove the existence of interactions between adsorbed organic species and the sepiolite surface (Aranda et al., 2008; Wicklein et al., 2010). In our study, the bands observed near $3720 \mathrm{~cm}^{-1}$ depend on the time and are produced most probably by free $\mathrm{Mg}(\mathrm{OH})_{2}$. (Ahlrichs et al., 1975) Consequently, these bands of HA-extracted sepiolite with increasing extraction time from 20 to $240 \mathrm{~min}$ showed no significant change in comparison to the raw sepiolite (Figure 8), indicating that its release from sepiolite did not alter the structure.

It is well known from the literature that in strongly alkaline media, Si tetrahedra of clay minerals undergo partial or total dissolution process, the Si-O-Si groups break and fixation of $\mathrm{OH}^{-}$takes place simultaneously, and the maximum quantities of polyvalent ions such as $\mathrm{Ca}^{2+}$, $\mathrm{Mg}^{2+}, \mathrm{Fe}^{2+}$ etc. released from the clay minerals (Martínez-Ramírez et al., 1996; Miura et al., 2012). The existence of these phenomena has been confirmed by SEM-EDAX analysis in spite of a widening of the band assigned to the $\mathrm{Si}-\mathrm{OH}$ vibrations which cannot be observed in the FTIR spectra of the sepiolite after extraction. SEM and EDAX results obtained at 240 min (Figure 10) able to separate organic matter from the inorganic one according to the procedure 
recommended by the International Humic Substances (Swift, 1996) have shown that the quantity of mono and polyvalent ions like $\mathrm{K}^{+}, \mathrm{Ca}^{2+}, \mathrm{Mg}^{2+}$ and $\mathrm{Al}^{3+}$ containing raw sepiolite decreased greatly and that of elemental oxygen increased after extraction depend on the high concentration of $\mathrm{OH}^{-}$ions in strong alkaline media. This helps breaking the sepiolite-humic acid metal bridges, suggesting that the humic acid strongly bonded through the soft and hard cations to basal surfaces of sepiolite and exchangeable cations, have an important role in sepiolite-HS complexation. It has been established by Varadachari et al. (1994) that humic acid is bonded through cations to the external surfaces and edges of illite and kaolinite. The exchangeable-cation-humic acid linkage is the strongest in illite compared with montmorillonite or kaolinite. Interaction of humic acid with montmorillonite disrupt its stacking arrangement and swelling favours complexation. In goethite and hematite, both cation bridging and surface coordination are involved in bonding (Varadachari et al., 1991; Varadachari et al., 1995; Varadachari et al., 1997; Varadachari et al., 2000). Moreover, the SEM image of HA-extracted sepiolite exhibited more uniform and regular structure than that of original sepiolite, and its large surfaces have been replaced by more clean and smooth surfaces (Figure 10). These changes in morphology would also result in changes in the physical and physico-chemical properties of the sepiolite, such as changes in color, particle size, stability, viscosity, surface area and porosity of the raw sepiolite. The semi-quantitative EDAX analyses of the raw and HA-extracted sepiolite showed that the percentages of $\mathrm{Si}, \mathrm{Al}$, $\mathrm{Mg}, \mathrm{Ca}$ and monovalent cation $\mathrm{K}$ in the solid residues were significantly reduced with increasing extraction time from $20 \mathrm{~min}$ to $240 \mathrm{~min}$. Decreasing the percentage of Si from $39.80 \%$ to $12.73 \%$ depending on the extraction time may explain the Si tetrahedra of sepiolite undergoing partial or total dissolution in strongly alkaline media (Martínez-Ramírez et al., 1996). In the EDAX analysis of the HA-extracted sepiolite, a strong decrease in the $\mathrm{Mg}, \mathrm{Ca}$ and $\mathrm{K}$ contents can be observed, indicating that electrically charged sites (mainly carboxyl groups) on HA may form metal complexes of high stability through chelation. This promotes the dissolution of metals from the sepiolite framework and makes up largely for the content of oxygen-containing functional groups, such as $\mathrm{COOH}$, phenolic $\mathrm{OH}$, and $\mathrm{C}=\mathrm{O}$ groups of various types in solution. Tan (1975) inferred similarly from changes in the infrared spectra of humic (and fulvic) acids which had previously been in contact with either kaolinite or montmorillonite.

Figure 11 presents the amounts of $\mathrm{Mg}^{2+}$ ions dissolved and of TOC released which increased slightly and almost linearly with time up to $240 \mathrm{~min}$. This finding would again suggest that mineral dissolution was not limited by the rate of metal cation diffusion out of the sepiolite structure, indicating that the greater the affinity of the metal cation for HA, the easier the dissolution of the cation from sepiolite surfaces.

The macromolecular configuration of humic acid strongly depends on $\mathrm{pH}$ and acidic functional groups on HAs (mainly carboxylic and phenolic) determine the binding characteristics of HAs for proton and other polyvalent cations. Senesi and Brunetti (1996) have reported that with increasing composting time and maturity of humic acid, there is loss of aliphatic groups richer in aromatic groups as more stable humic acid are formed. It is proposed that humic acid behave as "negatively charged polyelectrolytes" or "flexible linear colloids" at $\mathrm{pH}>3$ due to dissociation of carboxyl groups $(3<\mathrm{pH}<9)$ and phenolic hydroxyl groups ( $\mathrm{pH}>9$ ) (Tate et al., 1980). At least some components of HA are surface-active, and 
these components have been shown to form micelles in concentrated, alkaline aqueous solutions (Chilom and Rice, 2009). Our results indicate that the HA extracted from sepiolite at $\mathrm{pH}>11$ has a high molecular weight and a high humification degree and are aromatic. This forms around sepiolite grains the shorter and stiffer (more aromatic) chain-like humic acid segments to form structured pseudomicellar domains rather than aggregated structure at high pH as suggested by Ohashi and Nakazawa (1996) and Yates III et al. (1997) These structures are however transitional in nature, disintegrate as the metal ions gradually migrate to location where they form stable inner-sphere complexes with functional groups on the humic acid molecule (Engebretson and Von Wandruszka, 1998). Their formation and hydrodynamic sizes are strongly influenced by ionic size and metal ions (Von Wandruszka et al., 1997), especially $\mathrm{Mg}^{2+}$ and $\mathrm{Ca}^{2+}$ ions, $\mathrm{pH}$ and ionic strength. It is worth noting that although such structures of HAs could be responsible for the thermodynamically stable sepiolite suspensions (inhibited gel formation) in natural system as represented in Figure 12 and their sizes determined by Benli (2014), were also directly observed by high-resolution AFM images, were also changed in the range of $18-63 \pm 8 \mathrm{~nm}$ at $\mathrm{pH} 11.5$. In an early review (Frenkel et al., 1992; Tarchitzky et al., 1993), it was shown that humic and fulvic acids were added to reference clay suspensions, which always increased colloidal stability. The above results are consistent with the BET-surface area measurement data. To get an insight into the surface area and average pore diameter, the BET surface area measurements were performed on the original and HA-extracted sepiolite, and the results are illustrated in Table 3. It is clear that there is a strong relation between extracted HA, HA colloids, specific surface area, and microporosity in sepiolite.

Sepiolite BET measurements following upon extraction of organic matter showed that the specific surface area and pore volume of the HA extracted sepiolite are smaller than those of the raw sepiolite. After $20 \mathrm{~min}$, the specific surface area and pore volume of the HA extracted sepiolite strongly decreased from $358 \mathrm{~m}^{2} / \mathrm{g}$ to $125 \mathrm{~m}^{2} / \mathrm{g}$ and from 0.559 to $0.290 \mathrm{~cm}^{3} / \mathrm{g}$ then they re-increased from $125 \mathrm{~m}^{2} / \mathrm{g}$ to $247 \mathrm{~m}^{2} / \mathrm{g}$ and to $243 \mathrm{~m}^{2} / \mathrm{g}$, and from 0.290 to $0.315 \mathrm{~cm}^{3} / \mathrm{g}$ and to $0.380 \mathrm{~cm}^{3} / \mathrm{g}$, respectively, until they reached equilibrium. Sorption of HA molecules onto sepiolite surfaces at low extraction time effectively reduces the specific surface area mainly due to preferential sorption at reactive sites such as channels, rough surfaces, or micropores. Singer and Huang (1989) reported that the possibility that part of the humate had also penetrated the sepiolite channel surfaces cannot be entirely ruled out. This does not necessarily mean that HA molecules and their metal complexes are sorbed within the micropores. Because of the small size of micropores $(<2 \mathrm{~nm})$, penetration of HA molecules with a radius of gyration of $2.1 \mathrm{~nm}$ (Österberg et al., 1993) and their metal complexes which have the size range of $18-63 \pm 8 \mathrm{~nm}$ at $\mathrm{pH} 11.5$ (Benli, 2014), seems unlikely. A more reasonable explanation is sorption at the mouths of such pores or their blocking of sepiolite's micro/meso pores for larger structured pseudomicellar domains by organic macromolecules or both. This overall relationship implies that pore blockage is due to organic matter, although the blockage may occur because of either pore filling or simple coverage of the pore openings. However, the BET surface area value (approximately equal to the BET value of sepiolite extracted at $20 \mathrm{~min}$ ) obtained by subtracting the BET surface area value of extracted sepiolite at $240 \mathrm{~min}\left(243 \mathrm{~m}^{2} / \mathrm{g}\right)$ from the value of raw sepiolite $\left(358 \mathrm{~m}^{2} / \mathrm{g}\right)$ leads us to believe 
that some micropores are still filled by organic matter at the initial stage of HA extraction. Nevertheless, the uniformly reincrease in specific surface area and pore volume (e.g. decreasing pore diameter) of HA extracted sepiolite (Table 3) and the decrease in the amounts of polyvalent ions such as $\mathrm{Mg}^{2+}, \mathrm{Ca}^{2+}$, etc. released from the sepiolite (Figure 10) with increasing extraction times from 60 to 240 min suggested and confirmed that the large soluble HA molecules and polyvalent metal ions build up pseudomicelle (=HA macromolecules) under high alkaline environment based on the increased extraction time. This will favor their transfer from the sepiolite surfaces and/or the mouths of pores to the solution phase, resulting in the opening of closed micro/mesopores and increase of specific surface area and pore volume. Another possible explanation is that the HA macromolecules are sterically hindered from entering the channels of the sepiolite.

\section{Conclusions}

The UV-VIS spectral results of B-Sep showed that there is no correlation between $\mathrm{UV}_{254}$ and the amount of organic carbon released from sepiolite with increasing extraction time. This was confirmed by the subtraction $\mathrm{E}_{450}-\mathrm{E}_{700}$ which expresses the relative amount of extracted humic acid (HA), as a function of time, indicating the HA extraction reached its maximum fast within the first 20 min with no significant change afterwards.

The values for the $E_{4} / E_{6}$ ratio of humic substances extracted from the raw sepiolite were low and changed in a narrow range (3.19-3.28) during the increasing extraction time. The low values of humification index of B-Sep confirmed the presence of HA with higher, and similar molecular weight, particle size, humification degree and aromaticy.

The rapid extraction of humic acid and the small amount released had no apparent detectable structural alteration of the sepiolite. It can be concluded that humic acid containing many functional groups was presumably associated with a large quantity of silanol groups located on the external surface at the edges of structural channels of sepiolite preferentially through $\mathrm{H}$-bonds and/or surface complexation interactions between the functional groups in humic acid and dissolved metal cations $\left(\mathrm{M}^{\mathrm{n}+}\right)$, which are in good agreement with results of FTIR and SEM investigations.

SEM-EDAX analysis of the HA-extracted sepiolite showed a strong decrease in the $\mathrm{Mg}^{2+}$, $\mathrm{Ca}^{2+}$ and $\mathrm{K}^{+}$contents. This indicates that electrically charged sites (mainly carboxyl groups) on HA may form metal complexes of high stability through chelation which promotes the dissolution of metals from sepiolite framework. These are made up largely of oxygencontaining functional groups, such as $\mathrm{COOH}$, phenolic $\mathrm{OH}$, and $\mathrm{C}=\mathrm{O}$ groups of various types in solution.

HA extracted from sepiolite at $\mathrm{pH}>11$ has a high molecular weight and a high humification degree and aromatic and forms around sepiolite grains the shorter and stiffer (more aromatic) chain-like humic acid segments to form structured pseudomicellar domains rather than aggregates structure at high $\mathrm{pH}$ which could be responsible for the thermodynamically stable sepiolite suspensions (inhibited gel formation) in natural system. 
Overall the results showed that to get an insight into the surface area and average pore diameter, there is a strong relation between extracted HA from sepiolite, HA colloids and specific surface area, microporosity in sepiolite.

\section{Acknowledgments}

This research was supported by The Scientific and Technological Research Council of Turkey (TUBITAK) within the scope of International Postdoctoral Research Fellowship Programme. The work was undertaken in The Department of Civil \& Environmental Engineering, University of Surrey, United Kingdom.

\section{References}

Ahlrichs, J.L., Serna, C., Serratos,a J.M., 1975. Sructural hydroxyls in sepiolites. Clay Clay Miner. 23, $119-124$. Alothman, Z.A., 2012 A Review: Fundamental Aspects of Silicate Mesoporous Materials. Mater. 5, $2874-2902$.

Aranda, P., Kun, R., Martín-Luengo, M.A., Letaief, S., Dékány, I., Ruiz-Hitzky, E., 2008. Titania-sepiolite nanocomposites prepared by a surfactant templating colloidal route. Chem. Mater. 20, 84-89.

Arnarson, T.S., Keil, R.G., 2000. Mechanisms of pore water organic matter adsorption to montmorillonite. Mar. Chem. 71, 309-320.

Baham, J., Sposito, G., 1994. Adsorption of dissolved organic carbon extracted from sewage sludge on montmorillonite and kaolinite in the presence of metal ions. J. Environ. Qual. 23, 147-153.

Balcke, G.U., Kulikova, N.A., Hesse, S., Kopinke, F.D., Perminova, I.V., Frimmel, F.H., 2002. Adsorption of humic substances onto kaolin clay related to their structural features. Soil Sci. Soc. Am. J. 66, 1805-1812.

Benli, B., 2014. Effects of humic acid release from sepiolite on the interfacial and rheological properties of alkaline dispersions. Appl. Clay Sci. 102, 1-7.

Broekhoff, J.C.P., 1979. Mesopore determination from nitrogen sorption isotherms: Fundamentals, scope, limitations. Stud. Surf. Sci. Catal. 3, 663-684.

Burba, P., Shkinev, V., Spivakov, B.Y., 1995. On-line fractionation and characterization of aquatic humic substances by means of sequential-stage ultrafiltration. Fresen. J. Anal. Chem. 351, 74-82.

Chen, Y., Senesi, N., Schnitzer, M., 1977. Information provided on humic substances by $\mathrm{E}_{4} / \mathrm{E}_{6}$ ratios. Soil Sci. Soc. Am. J. 41, 352-358.

Chen, J., Gu, B., LeBoeuf, E.J., Pan, H., Dai, S., 2002. Spectroscopic characterization of the structural and functional properties of natural organic matter fractions. Chemosphere. 48, 59-68.

Chen, C., Wang, X., Jiang, H., Hu, W., 2007. Direct observation of macromolecular structures of humic acid by AFM and SEM. Coll. Surf. A. 302, 121-125.

Chen, C., Wang, F., Liang, J., Tang, Q., Chen, Y., 2012. Zeta potential of sepiolite in aqueous system. Adv. Mater. Res. 427, 208-211.

Chilom, G., Rice, J. A., 2009. Organo-clay complexes in soils and sediments. In Biophysico-Chemical Processes Involving Natural Nonliving Organic Matter in Environmental Systems (eds. N. Senesi, B. Xing and P. M. Huang). John Wiley \& Sons, New Jersey. pp. 387.

Chiou, C.T., Malcolm, R.L., Brinton, T.I., Kile, D.E., 1986. Water solubility enhancement of some organic pollutants and pesticides by dissolved humic and fulvic acids. Environ. Sci. Technol. 20(5), 502-508.

Chorover, J., Amistadi, M.K., 2001. Reaction of forest floor organic matter at goethite, birnessite and smectite surfaces. Geochim. Cosmochim. Acta. 6, 95-109.

Collins, M.J., Bishop, A.N., Farrimond, P., 1995. Sorption by mineral surfaces: rebirth of the classical condensation pathway for kerogen formation. Geochim. Cosmochim. Acta. 59, 2387-2391.

Cunha, T.J.F., Novotny, E.H., Madari, B.E., Martin-Neto, L., de O Rezende, M.O., Canelas, L.P., de M Benites, V., 2009. Spectroscopy characterization of humic acids isolated from Amazonian dark earth soils (Terra Preta De Índio). In Amazonian Dark Earths: Wim Sombroek's Vision. Springer, Netherlands. 
Çelik, M.S., 2004. Electrokinetic behavior of clay surfaces, in clay surfaces: Fundamentals and applications. In nterface Science and Technology Series (eds. F. Wypych). Academic Press, pp. 57-89.

Dick, D.P., Burbab, P., 1999. Extraction kinetics and molecular size fractionation of humic substances from two Brazilian soils. J. Brazil. Chem. Soc. 10(2), 146-152.

Ding, F., Cai, J.G., Song, M.S., Yuang, P., 2013. The relationship between organic matter and specific surface area in $<2 \mu \mathrm{m}$ clay size fraction of muddy source rock. Sci. China Earth Sci. 56(8), 1343-1349.

EN 1097-3, 1998. Test for Mechanical and Physical Properties of Aggregates-Part 3: Determination of Loose Bulk Density and Voids. European Committee for Standardization, Brüssel.

Enev, V., Pospíšilová, L., Klučáková, M., Liptaj, T., Doskočil, L., 2014. Spectral characterization of selected humic substances. Soil Water Res. 9, 9-17.

Engebretson, R.R., Von Wandruszka, R., 1998. Kinetic aspects of cation-enhanced aggregation in aqueous humic acids. Environ. Sic. Technol. 32, 488-493.

Eren, E., Cubuk, O., Ciftci, H., Eren, B., Caglar, B., 2010. Adsorption of basic dye from aqueous solutions by modified sepiolite: Equilibrium, kinetics and thermodynamics study. Desalination 252, 88-96.

Evans, L.T., Russell, E.W., 1959. The adsorption of humic and fulvic acids by clays. J. Soil Sci. 10, 119-132.

Feng, X., Simpson, A.L., Simpson, M.J., 2005. Chemical and mineralogical controls on humic acid sorption to clay mineral surfaces. Org. Geochem. 36, 553-1566.

Feng, X.J., Simpson, A.J., Simpson, M.J., 2006. Investigating the role of mineralbound humic acid in phenanthrene sorption. Environ. Sci. Technol. 40, 3260-3266.

Frenkel, H., Fey, M.V., Levy, G.J., 1992. Organic and inorganic anion effects on reference and soil clay critical flocculation concentration. Soil Sci. Soc. Am. J. 56, 1762-1766.

Frimmel, F.H., Christman, R.F., 1988. Humic Substances and Their Role in The Environment, John Wiley \& Sons, New York.

Frimmel, F.H., 1998. Characterization of natural organic matter as major constituents in aquatic systems. J. Contam. Hydrol. 35 (1-3), 201-216.

Frimmel, F.H., Abbt-Braun, G., Heumann, K.G., Hock, B., Ludmann, H.D., Spiteller, M., 2002. Refractory Organic Substances in the Environment. Wiley-VCH, Weinheim.

Frost, R.L., Locos, O.B., Ruan, H., Kloprogge, J.T., 2001. Near-infrared and mid-infrared spectroscopic study of sepiolites andpalygorskites. Vibrational. Spect. 27, 1-13.

Furukawa, Y., 2000. Energy-altering transmission electron microscopy (EFTEM) and electron energy-loss spectroscopy (EELS) investigation of clay-organic matter aggregates in aquatic sediments. Org. Geochem. 31(7-8), 735-744.

Giovanela, M., Crespo, J.S., Antunes, M., Adametti, D.S., Fernandes, A.N., Barison, A., Da Silva, C.W.P., Guegan, R., Motelica-Heino, M., 2010. Chemical and spectroscopic characterization of humic acids extracted from the bottom sediments of a Brazilian subtropical microbasin. J. Mol. Struct. 981(1-3), 111119.

Golden, D.C., Dixon, J.B., Shadfan, H., Kippenberger, L.A., 1985. Palygorskite and sepiolite alteration to smectite under alkaline conditions. Clay Clay Miner. 33(1), 44-50.

Greenland, D. J., 1971. Interactions between humic and fulvic acids and clays. Soil Sci. 111(1), 34-41.

Gu, B., Schmitt, J., Chen, Z., Liang, L., McCarthyt, J. F. (1994) Adsorption and desorption of natural organic matter on iron oxide: mechanisms and models. Environ. sci. Technol. 28, 38-48.

Helms, J.R., Stubbins, A., Ritchie, J.D., Minor, E.C., Kieber, D.J., Mopper, K., 2008. Absorption spectral slopes and slope ratios as indicators of molecular weight, source, and photobleaching of chromophoric dissolved organic matter. Limnol. Oceanogr. 53, 955-969.

Kadir, S., Baş, H., Karakaş, Z., 2002. Origin of sepiolite and loughlinite in a neogene volcano-sedimentary lacustrine environment, Mihalıççk-Eskişehir, Turkey. Can. Mineral. 40, 1091-1102.

Kaiser, K., Guggenberger, G., 1997. Mineral surfaces and soil organic matter. Eur. J. Soil. Sci. 54, 219-236.

Khalaf, M., Kohl, S., Klumpp, E., Rice, J., Tombácz, E., 2003. Comparison of sorption domains in molecular weight fractions of a soil humic acid using solid-state ${ }^{19}$ F NMR. Environ. Sci. Technol. 37, 2855-2860.

Kojdecki, M.A., Bastida, J., Pardos, P., Amorós, P., 2005. Crystalline microstructure of sepiolite influenced by grinding. J. Appl. Crystallogr. 38, 888-899. 
Kononova, M.M., 1982. Materia organica del suelo: su naturaleza, propiedades y métodos de investigación. In Nueva Enciclopedia de Agricultura Materia Organica del Suelo (eds. S. A. Oikos-Tau). Barcelona, Spain.

Kordel, W., Dassenakis, M., Lintelmann, J., Padberg, S., 1997. The importance of natural organic material for environmental processes in waters and soils. Pure. Appl. Chem. 69 (7), 1571-1600.

Kretzschmar, R., Sticher, H., Hesterberg, D., 1997. Effects of adsorbed humic acid on surface charge and flocculation of kaolinite. Soil Sci. Soc. Am. J. 61(1), 101-108.

Ksiezopolska, A., Pazus, M., 2011. Surface properties of bentonite and illite complexes with humus acids. Clay Miner. 46, 149-156.

Kumada, K., 1988. Chemistry of Soil Organic Matter, Elsevier.

Laor, Y., Farmer, W.J., Aochi, Y., Strom, P.F., 1998. Phenantren binding and sorption to dissolved and to mineral-associated humic acid. Water Res. 32, 1923-1931.

Lescano, L., Castillo, L., Marfil, S., Barbosa, S., Maiza, P., 2014. Alternative methodologies for sepiolite defibering. Appl. Clay Sci. 95, 378-382.

Majzik, A., Tombácz, E., 2007. Interaction between humic acid and montmorillonite in the presence of calcium ions II. Colloidal interactions: Charge state, dispersing and/or aggregation of particles in suspension. Org. Geochem. 38(8), 1330-1340.

Martienssen, W., 2009. Landolt-Börnstein / New Series. Springer-Verlag, Berlin.

Martinez-Ramirez, S., Puertas, F., Blanco-Varela, M.T., 1996. Stability of sepiolite in neutral and alkaline media at room temperature. Clay Min. 31, 225-232.

Martinez, R.E., Sharma, P. Kappler, A., 2010. Surface binding site analysis of $\mathrm{Ca}^{2+}$-homoionized clay-humic acid complexes. J. Colloid Interf. Sci. 352, 526-534.

McDonald, S., Bishop, A.G., Prenzler, P.D., Robards, K., 2004. Analytical chemistry of freshwater humic substances. Anal. Chim. Acta. 527, 105-124.

Miura, A., Nakazawa, K., Takei, T., Kumada, N., Kinomura, N., Ohki, R., Koshiyama, H., 2012. Acid-, base-, and heat-induced degradation behavior of Chinese sepiolite. Ceram. Int. 38, 4677-4684.

Mortland, M.M., 1970. Clay-organic complexes and their interactions. Adv. Agron. 22, 75-117.

Murphy, E.M., Zachara, J.M., Smith, S.C., Phillips, J.L., Wietsma, T.W., 1994. Interaction of hydrophobic organic compounds with mineral-bound humic substances. Environ. Sci. Technol. 28, 1291-1299.

Nadi, M., 2012. Characterization of soil humic substances in Hungarian and Iranian soils. Ph. D. thesis. Szent István University, Gödöllö, Hungarian.

Namjesnik-Dejanovic, K., Maurice, P.A., Aiken, G.R., Cabaniss, S., Chin, Y.P., Pullin, M.J., 2000. Adsorption and6fractionation of a muck fulvic acid on kaolinite and goethite at pH 3.7, 6, and 8. Soil Sci. 165, 545-559.

Nayak D.C., Varadachari, C., Ghosh, K., 1990. Influence of organic acidic functional groups of humic substances in complexation with clay minerals. Soil Sci. 149(5), 268-271.

Ohashi H., Nakazawa H., 1996. The microstructure of humic acid-montmorillonite composites. Clay Min. 31, 347-354.

Österberg, R., Lindovist, I., Mortensen, K., 1993. Particle size of humic acid. Soil Sci. Soc. Am. J. 57(1), 283285.

Peña-Méndez, E.M., Havel, J., Patočka, J., 1999. Humic substances-compounds of still unknown structure: applications in agriculture, industry, environment, and biomedicine. J. Appl. Biomed. 3, 13-24.

Pokorná, L., Gajdošová, D., Mikeska, S., Homoláč, P., Havel, J., 2001. The Stability of Humic Acids in Alkaline Media. Fifth Humic Substances Seminar, Boston, USA.

Radian, A., Mishael, Y., 2012. Effect of Humic acid on pyrene removal from water by polycation-clay mineral composites and activated carbon. Environ. Sci. Technol. 46, 6228-6235.

Rav-Acha, C., Rebhun, M., 1992. Binding of organic solutes to dissolved humic substances and its effects on adsorption and transport in theaquatic environment. Water Res. 26(12), 1645-1654.

Ruiz-Hitzky, E., 2001. Molecular access to intracrystalline tunnels of sepiolite, J. Mater. Chem. 11, 86-91.

Saada, A., Gaboriau, H., Cornu, S., Bardot, F., Villiéras, F., Croué, J.P., 2003. Adsorption of humic acid onto a kaolinitic clay studied by high-resolution argon adsorption volumetry. Clay Miner. 38, 433-443.

Sabah, E., Mart, U., Çınar, M., Çelik, M.S., 2007. Zeta potentials of sepiolite suspensions in concentrated monovalent electrolytes. Separ. Sci. Technol. 42, 2275-2288. 
Sarıkaya, Y., 1981. Effect of outgassing temperature on surface area of sepiolite. Comm. of Faculty of Science at University of Ankara. 27, 45-49.

Satterberg, J., Arnarson, T.S., Lessard, E.J., 2003. Sorption of organic matter from four phytoplankton species to montmorillonite, chlorite and kaolinite in seawater. Mar. Chem. 81, 11-18.

Schlautman, M.A., Morgan, J.J., 1994. Adsorption of aquatic humic substances on colloidal-size aluminum oxide particles: influence of solution chemistry. Geochim. Cosmochim. Acta. 58, 4293-4303.

Senesi, N., Brunetti, G., 1996. Chemical and physico-chemical parameters for quality evaluation of humic substances produced during composting. In The Science of Composting (eds. M. de Bertoldi, P. Sequi, B. Lemmes and T. Papi). Springer, Netherlands.

Serratosa, J.M., 1979. Surface properties of fibrous clay minerals (palygorskite and sepiolite). Proceedings of the VI. international clay conference, Oxford, UK.

Sevim, A.M., Hojiyev, R., Gül, A., Çelik, M.S., 2011. An investigation of the kinetics and thermodynamics of the adsorption of a cationic cobalt porphyrazine onto sepiolite. Dyes Pigments. 88(1), 25-38.

Shields, J.E., Lowell, S., Thomas, M.A., Thommes, M., 2004. Characterization of Porous Solids and Powders: Surface Area, Pore Size and Density. Kluwer Academic Publisher, Boston.

Shin, D., Chung, Y., Choi, Y., Kim, J., Park, Y., Kum, H., 1999. Assessment of disinfection by-products in drinking water in Korea. J. Expo. Anal. Environ. Epidemiol. 9(3), 192-199.

Shuali, U., Nir, S., Rytwo, G.P., 2011. Adsorption of surfactants, dyes and cationic herbicides on sepiolite and palygorskite: Modifications, applications and modelling. In Developments in Palygorskite-Sepiolite Research (eds. E. Galan and A. Singer). Elsevier.

Simpson, A.J., Simpson, M.J., Kingery, W.L., Lefebvre, B.A., Moser, A., Williams, A.J., Kvasha, M., Kelleher, B.P., 2006. The application of ${ }^{1} \mathrm{H}$ high-resolution magic-angle spinning NMR for the study of clay-organic associations in natural and synthetic complexes. Langmuir 22, 4498-4503.

Sing, K.S.W., Everett, D.H., Haul, R.A.W., Moscou, L., Pierotti, R.A., Rouquerol, J., Siemieniewska, T., 1985. Reporting physisorption data for gas/solid systems with special reference to the determination of surface area and porosity. Pure Appl. Chem. 57, 603-619.

Singer, A., Huang, P.M., 1989. Adsorption of humic acid by palygorskite and sepiolite. Clay Miner. 24, 561564.

Specht, C.H., Kumke, M.U., Frimmel, F.H., 2000. Characterization of NOM adsorption to clay minerals by size exclusion chromatography. Water Res. 34, 4063-4069.

Spitzy A., Leenheer, J., 1991. Dissolved organic matter in rivers, in Degens, E.T., Kempe, S., Richey, J.E. (Eds), Biogeochemistry of Major World Rivers. John Wiley \& Sons, New York.

Sposito, G., 2008. Surface Chemistry of Soils, Oxford University Press, Oxford.

Stevenson, F.J., 1994. Humus Chemistry: Genesis, Composition, Reactions. Second ed. John Wiley \& Sons, New York.

Swift, R.S., 1996. Organic Matter Characterization. Soil Science Society of America, Madison.

Suárez, M., García-Romero, E., 2012. Variability of the surface properties of sepiolite. Appl. Clay Sci. 67-68, 72-82.

Summers, R.S., Cornel, P.K., Roberts, P.V., 1987. Molecular size distribution and spectroscopic characterization of humic substances. Sci. Total Environ. 62, 27-37.

Tan, K.H., 1975. The catalytic decomposition of clay minerals by complex reaction with humic and fulvic acid. Soil Sci. 120, 188-194.

Tan, K.H., 1986. Degradation of soil minerals by organic acids. In Interactions of Soil Minerals with Natural Organics and Microbe (eds. P.M. Huang and M. Schnitzer). SSSA Special Publication 17: Soil Sci. Soc. Am. Inc., Madison.

Tarchitzky, J., Chen, Y., Banin, A., 1993. Humic substances and pH effects on sodium- and calciummontmorillonite flocculation and dispersion. Soil Sci. Soc. Am. J. 57, 367-372.

Tate, K.R., Theng, B.K.G., 1980. Organic matter and its interaction with inorganic soil constituents. In: Theng, B.K.G. (Ed.), Soils with Variable Charge. New Zealand Soc. Soil Sci. Palmerston North.

Theng, B.K.G., Tate, K.R., 1989. Interactions of clays with soil organic constituents. Clay Res. 8, 1-10.

Theng, B.K.G., 2012. Humic substances. Dev. Clay Sci. 4, 391-456. 
Tombácz, E., Szekeres, M., Baranyi, L., Michéli, E., 1998. Surface modification of clay minerals by organic polyions. Colloid. Surface. A. 141, 379-384.

Tombácz, E., Libor, Z., Illes, E., Majzik, A., Klumpp, E., 2004. The role of reactive surface sites and complexation by humic acids in the interaction of clay mineral and iron oxide particles. Org. Geochem. 35, 257-267.

Tunç, S., Duman, O., Uysal, R., 2008. Electrokinetic and rheological behaviors of sepiolite suspensions in the presence of poly(acrylic acid sodium salt)s, polyacrylamides, and poly(ethylene glycol)s of different molecular weights. J. Appl. Polym. Sci. 109, 1850-1860.

UBC, 2015. LFS: SoilWeb/Soil components/organic components. The University of British Colombia Website. http://wiki.ubc.ca/LFS:SoilWeb/Soil_Components/Organic_Components.

Varadachari, C., Mondal, A. H., Ghosh, K., 1995. The influence of crystal edges on clay-humus complexation, Soil Sci. 159, 185-190.

Varadachari, C., Mondal, A. H., Ghosh, K., 1991. Some aspects of clay-humus complexation: Effect of exchangeable cations and lattice charge. Soil Sci. 151(3), 220-227.

Varadachari, C., Mondal, A. H., Nayak, D. C., Ghosh, K., 1994. Clay-humus complexation: effect of pH and the nature of bonding. Soil Biol. Biorhem. 26(9), 1145-1149.

Varadachari, C., Mondal, A. H., Ghosh, K., 1995. The influence of crystal edges on clay-humus complexation, Soil Sci. 159(3), 185-190.

Varadachari, C., Chattopadhyay, T., Ghosh, K., 1997. Complexation of humic substances with oxides of iron and aluminum. Soil Sci. 162, 28-34.

Varadachari, C., Chattopadhyay, T., Ghosh, K., 2000. The crystallo-chemistry of oxide-humus complexes. Aust. J. Soil Res. 38, 789-806.

Vdović, N., 2001. Electrokinetic behaviour of calcite-the relationship with other calcite properties. Chem. Geol. 177, 241-248.

Vermeer, A.W.P., van Riemsdijk, W.H., Koopal, L.K., 1998. Adsorption of humic acid to mineral particles. 1. Specific and electrostatic interactions. Langmuir 14, 2810-2819.

Vermeer, A.W.P., Koopal, L.K., 1998. Adsorption of humic acids to mineral particles. 2. Polydispersity effects with polyelectrolyte adsorption. Langmuir 14, 4210-4216.

Von Wandruszka, R., Ragle, C., Engebretson, R., 1997. The role of selected cations in the formation of pseudomicelles in aqueos humic acid. Talanta 44, 805-809.

Vučelić, D., Simić, D., Kovačević, O., Dojčinović, M., Mitrović, M., 2002. The effects of grinding on the physicochemical characteristics of white sepiolite from Golesh. J. Serbian Chem. Soc. 67(3), 197-211.

Wang, K.J., Xing, B.S., 2005. Structural and sorption characteristics of adsorbed humic acid on clay minerals. J. Environ. Qual. 34, 342-349.

Wattel-Koekkoek, E.J.W., van Genuchten, P.P.L., Buurman, P., van Lagen, B., 2001. Amount and composition of clay associated soil organic matter in a range of kaolinitic and smectitic soils. Geoderma 99, $27-49$.

Wattel-Koekkoek, E.J.W., 2002. Clay-associated organic matter in kaolinitic and smectitic soils. Ph. D. thesis. Wageningen University, Wageningen, The Netherlands.

Wershaw, R.L., Pinckney, D.J., 1980. Isolation characterization of clay-humic complexes. In Contaminants and Sediments, Analysis, Chemistry and Biology (ed. A. Baker). Ann Arbor Science Publishers, Ann Arbor.

Werhaw, R.L., 1986. A new model for humic materials and their interactions with hydrophobic organic chemicals in soil-water or sediment-water system. J. Contam. Hydrol. 1, 29-45.

Wicklein, B., Darder, M., Aranda, P., Ruiz-Hitzky, E., 2010. Bio-organoclays based on phospholipids as 1mmobilization hosts for biological species. Langmuir 26(7), 5217-5225.

Yang, K., Xing, B., 2009. Adsorption of fulvic acid by carbon nanotubes from water. Environ. Pollut. 157, 0951100 .

Yates, I. Engebretson, R.R., Haakenson, T.J., von Wandruszka, R., 1997. Immobilization of aqueous pyrene by dissolved humic acid. Anal. Chim. Acta. 356, 295-300.

Zhang, L., Luo, L., Zhang, S., 2012. Integrated investigations on the adsorption mechanisms of fulvic and humic acids on three clay minerals. Colloid. Surface. A. 406, 84-90.

Zhou, J.L., Rowland, S., Mantoura, R.F.C., 1994. The formation of humic coatings on mineral particles under simulated estuarine conditions - a mechanistic study. Water Res. 28, 571-579. 
Table 1. Characteristics of the raw sepiolite.

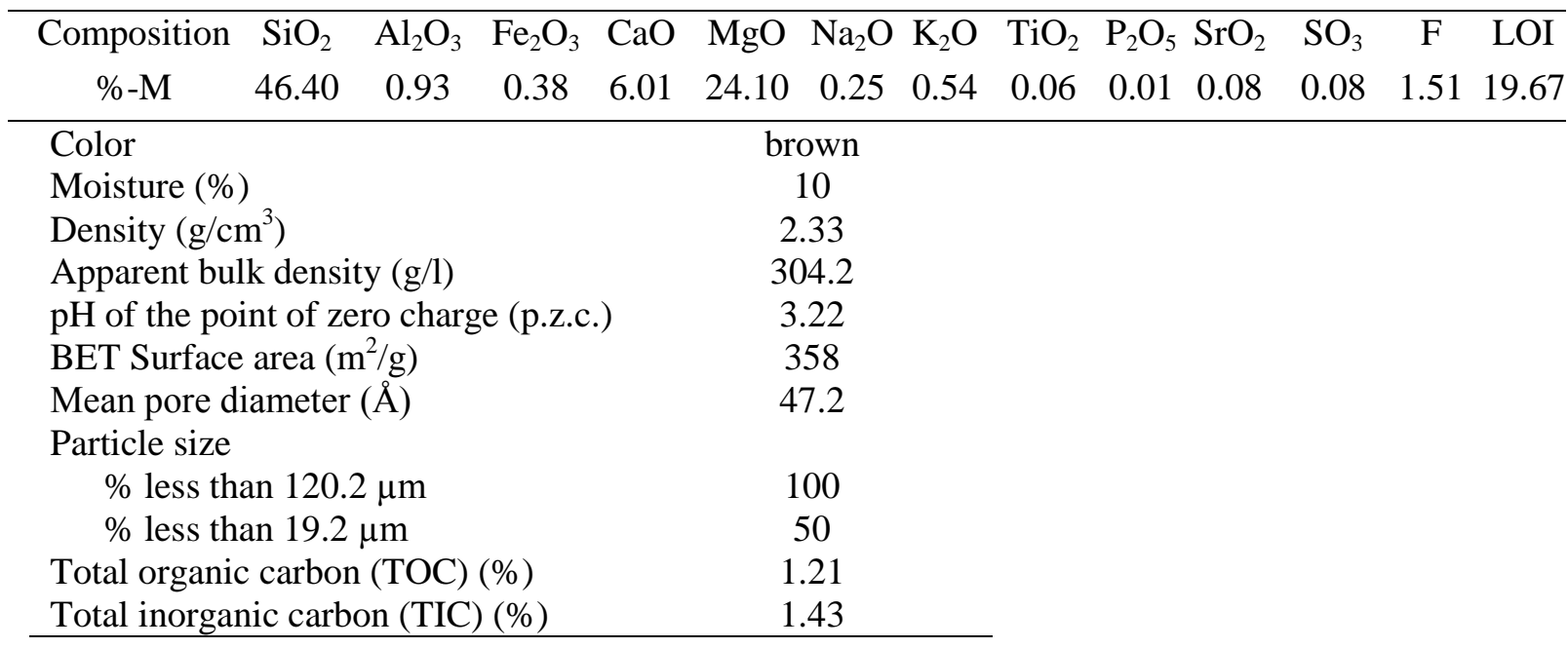

Table 2. UV-Vis absorbance parameters from 20 to 240 min of the HA extracted from raw sepiolite.

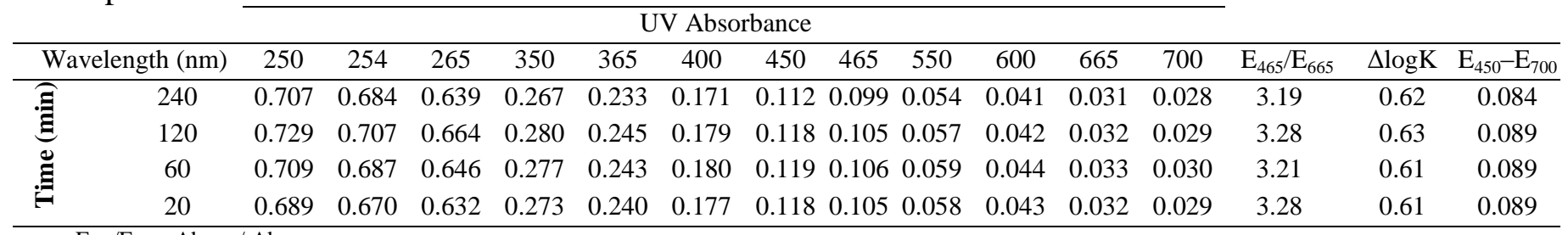

$\mathrm{E}_{465} / \mathrm{E}_{665}=\mathrm{Abs}_{465} / \mathrm{Abs}_{665}$

$\Delta \log \mathrm{K}=\log \mathrm{Abs}_{400}-\log \mathrm{Abs}_{600}$

$\mathrm{E}_{450}-\mathrm{E}_{700}=\mathrm{Abs}_{450} / \mathrm{Abs}_{700}$

Table 3. Some physico-chemical charasterictics of the raw sepiolite befor and after extraction depend on the extraction time.

\begin{tabular}{ccccccc}
\hline \multirow{2}{*}{$\begin{array}{c}\text { Extraction } \\
\text { Time }\end{array}$} & \multicolumn{2}{c}{ BET Surface Area $\left(\mathrm{m}^{2} / \mathrm{g}\right)$} & \multicolumn{2}{c}{ Pore Diameter $(\AA)$} & \multicolumn{2}{c}{ Pore Volume $\left(\mathrm{cm}^{3} / \mathrm{g}\right)$} \\
\cline { 2 - 7 } & $\begin{array}{c}\text { Befor } \\
\text { extraction }\end{array}$ & $\begin{array}{c}\text { After } \\
\text { extraction }\end{array}$ & $\begin{array}{c}\text { Befor } \\
\text { extraction }\end{array}$ & $\begin{array}{c}\text { After } \\
\text { extraction }\end{array}$ & $\begin{array}{c}\text { Befor } \\
\text { extraction }\end{array}$ & $\begin{array}{c}\text { After } \\
\text { extraction }\end{array}$ \\
\hline 20 & & 125 & & 56.56 & & 0.290 \\
60 & \multirow{2}{*}{358} & 247 & 47.20 & 36.84 & 0.559 & 0.315 \\
120 & 245 & & 35.69 & & 0.378 \\
240 & & 243 & & 35.52 & & 0.380 \\
\hline
\end{tabular}




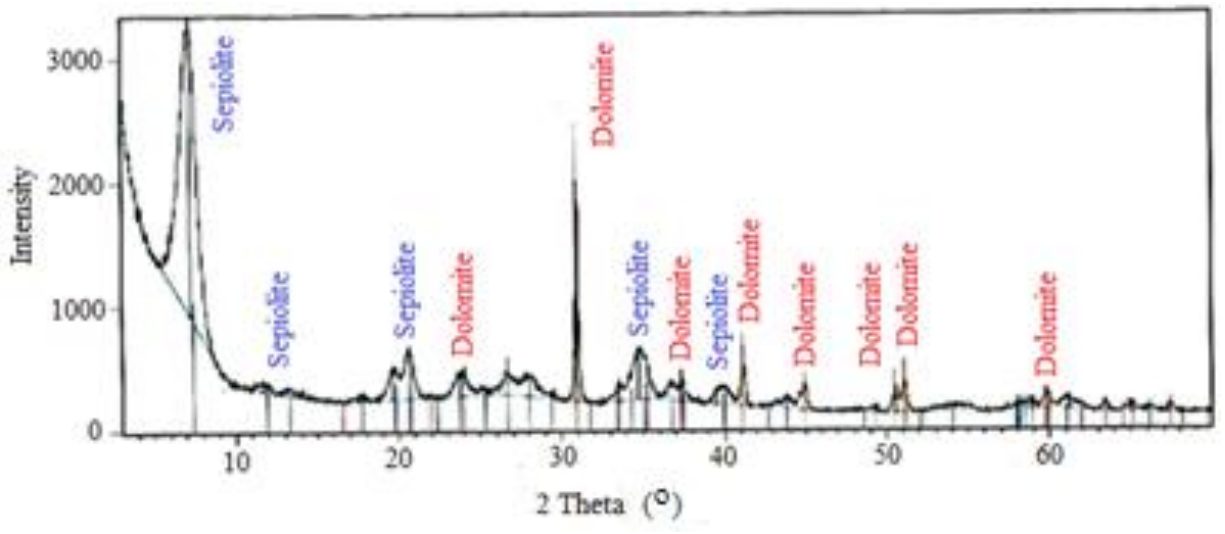

Fig. 1. X-Ray diffractograms of raw sepiolite.

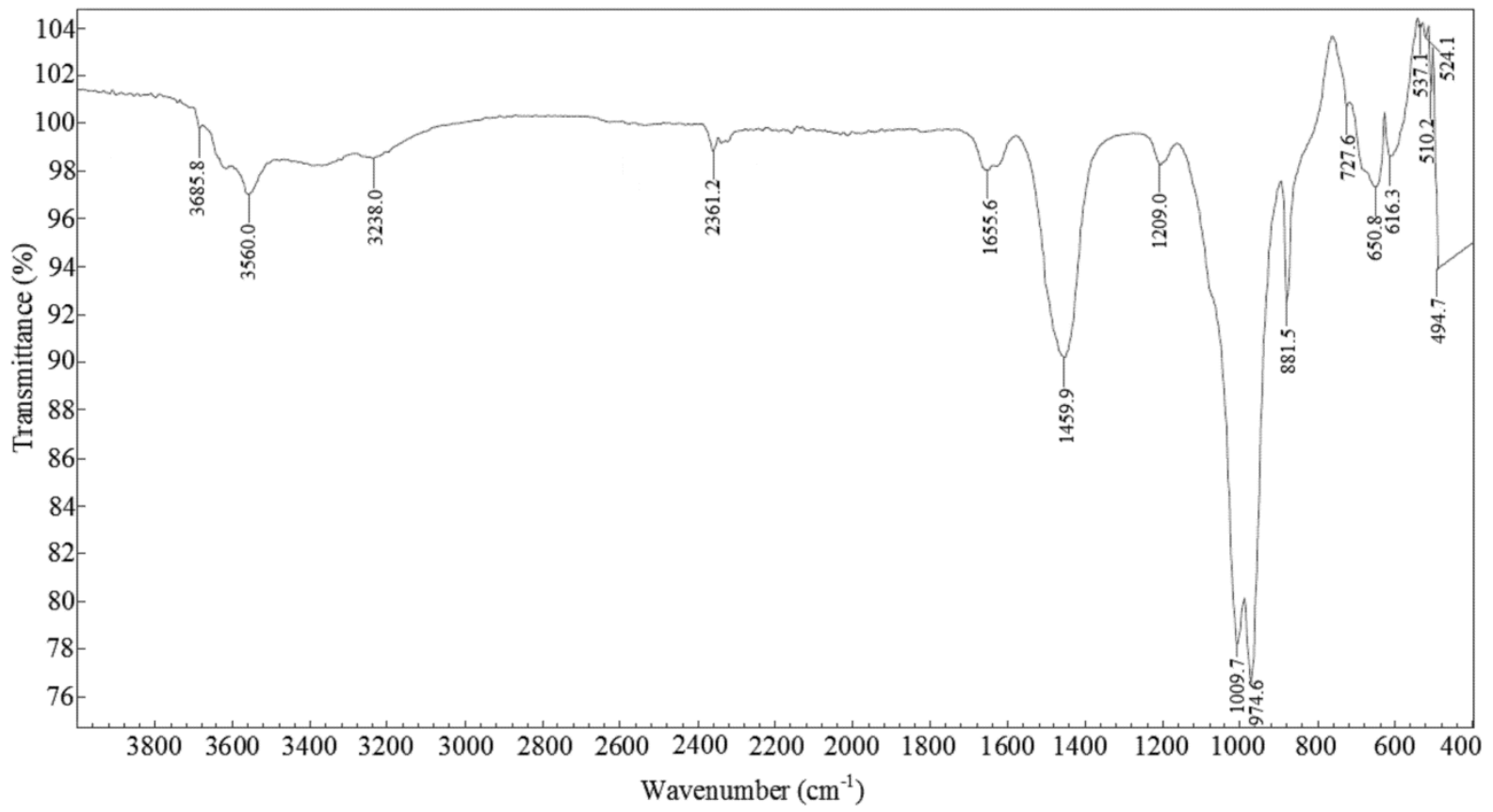

Fig. 2. FTIR spectra of raw sepiolite. 


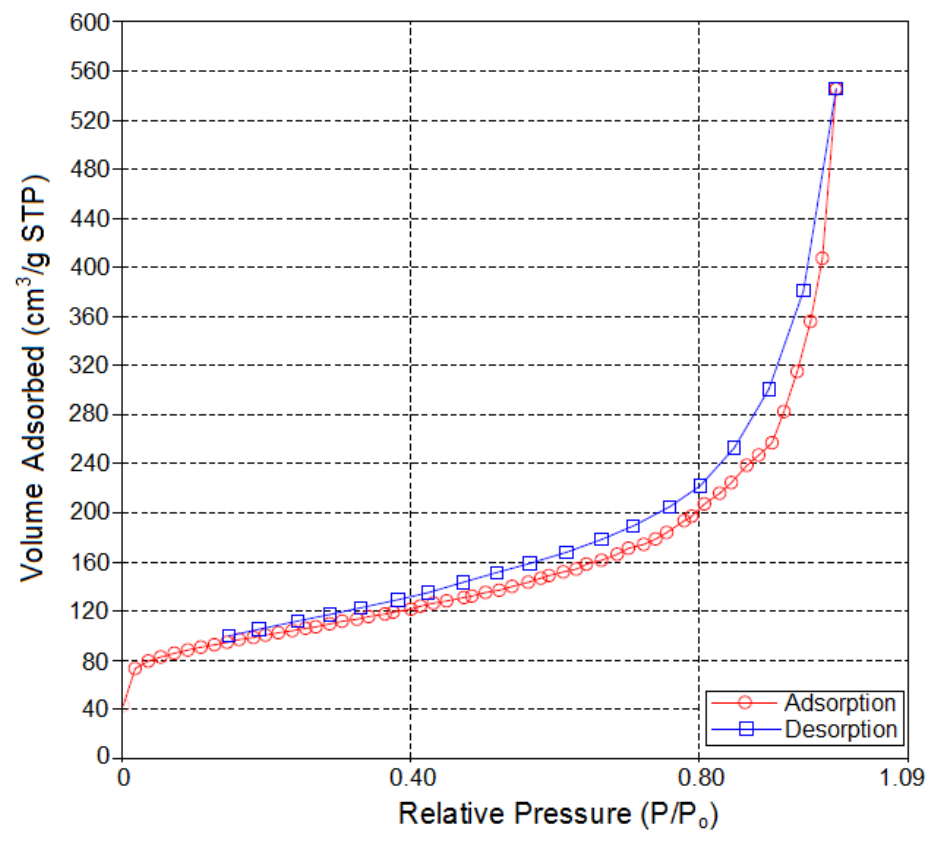

Fig. 3. $\mathrm{N}_{2}$ adsorption and desorption isotherms at $-196^{\circ} \mathrm{C}$ for raw sepiolite.

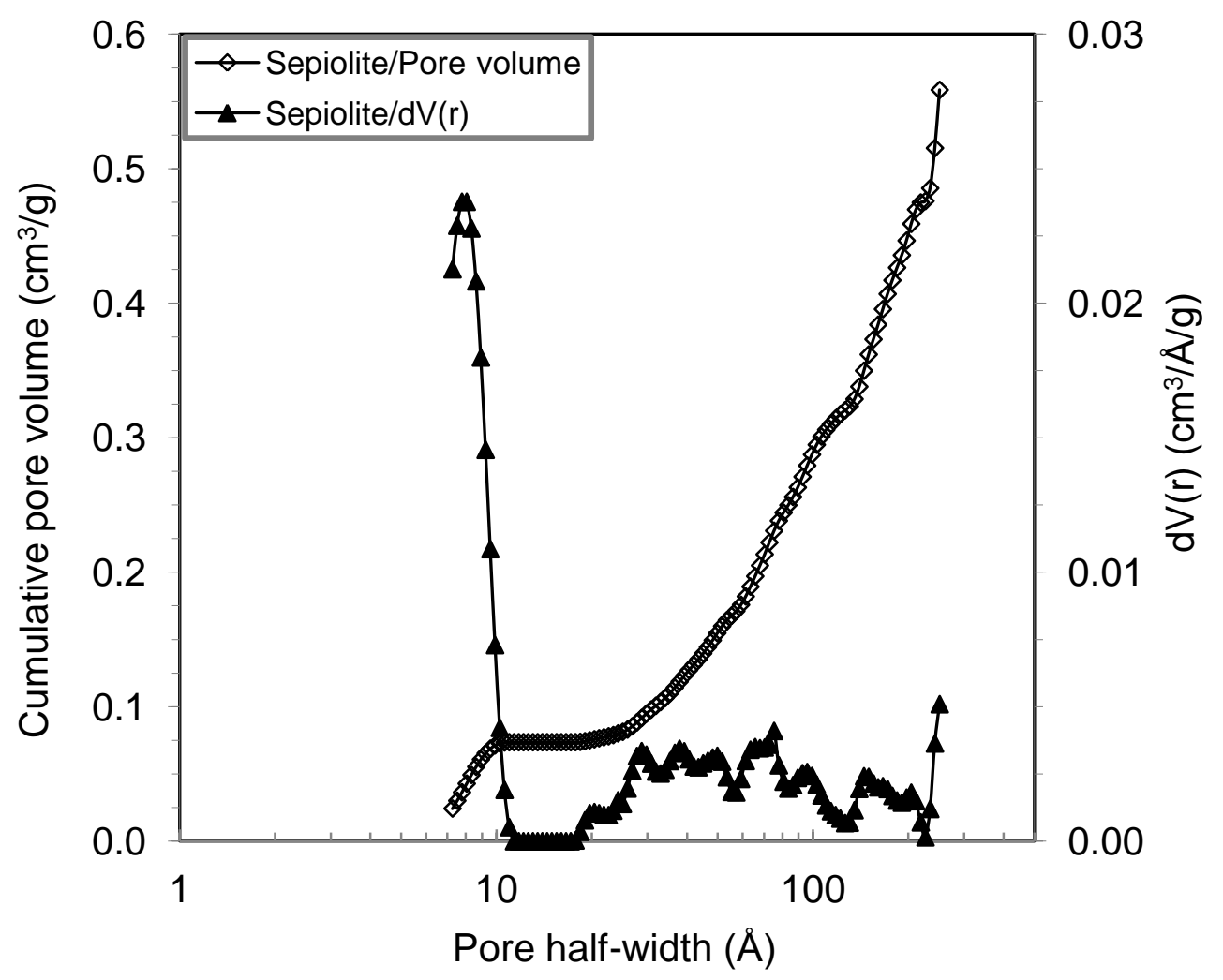

Fig. 4. Cumulative pore volume and pore-size distribution curves for raw sepiolite. 

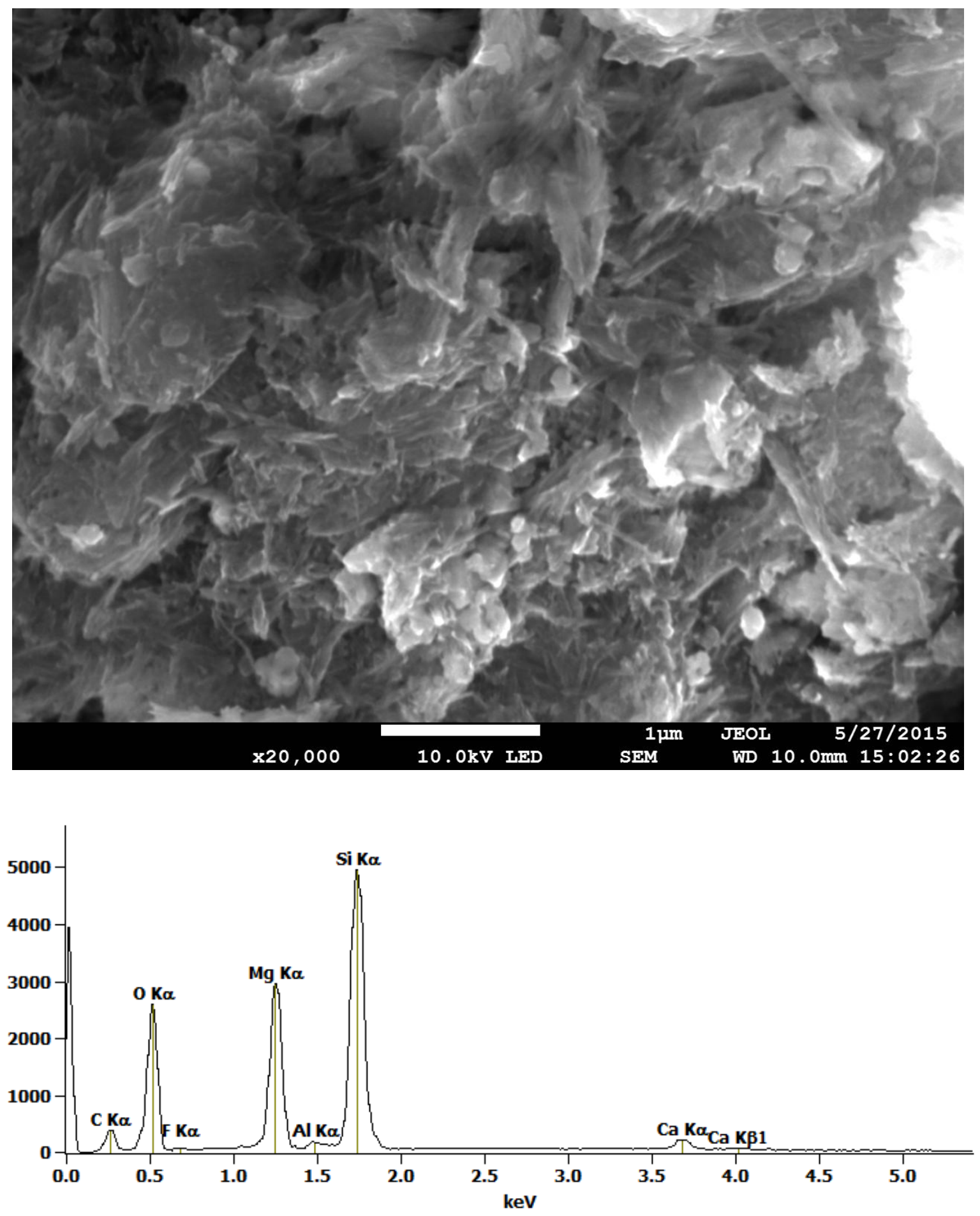

Fig. 5. SEM image and semi-quantitative (EDX) analysis of raw sepiolite. 


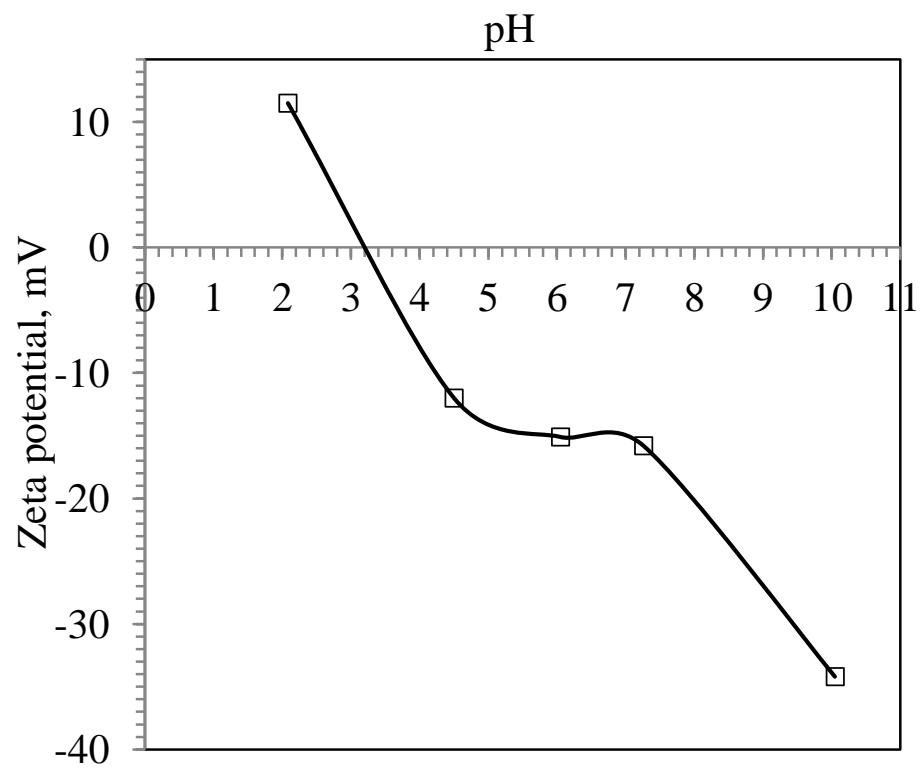

Fig. 6. The variation of zeta potential of raw sepiolite with $\mathrm{pH}$ values.

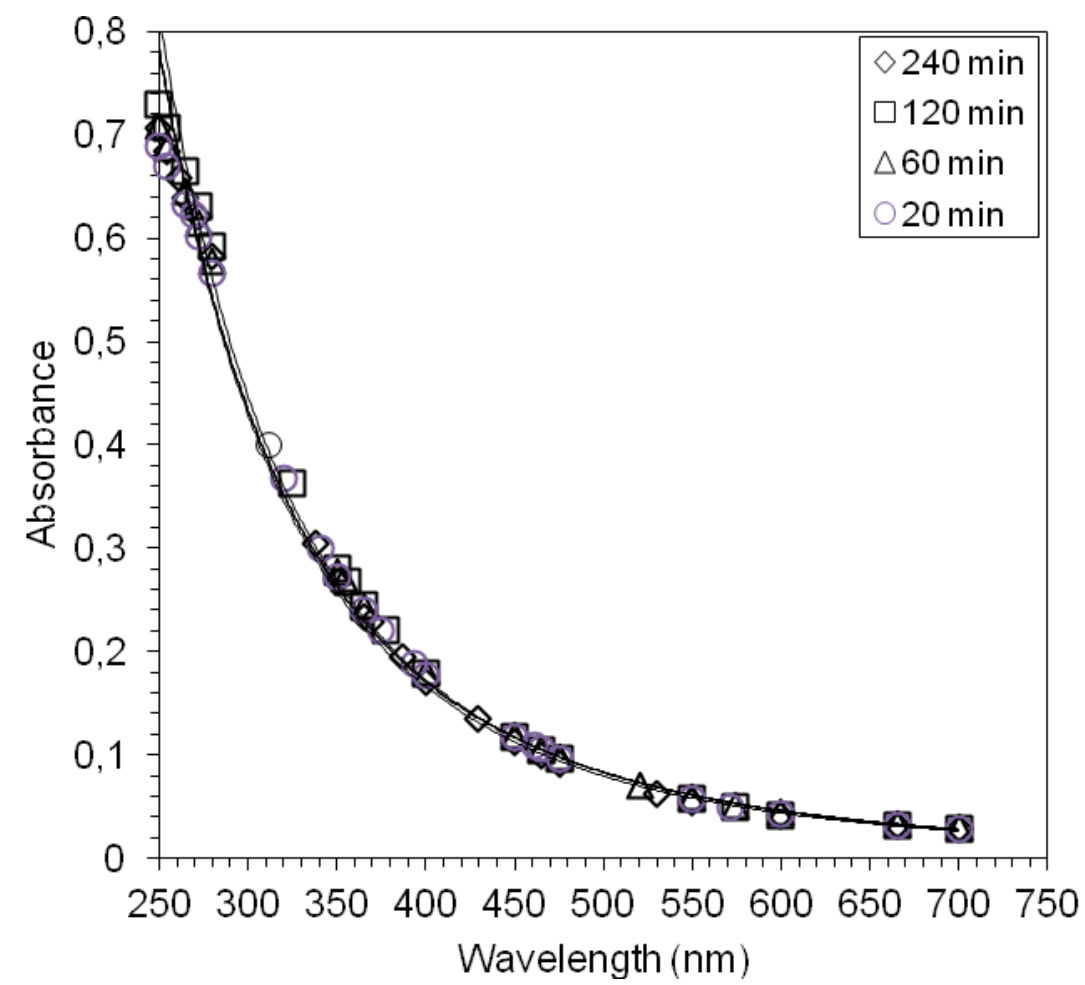

Fig. 7. UV-vis absorbance of humic substances extracted from raw sepiolite. 


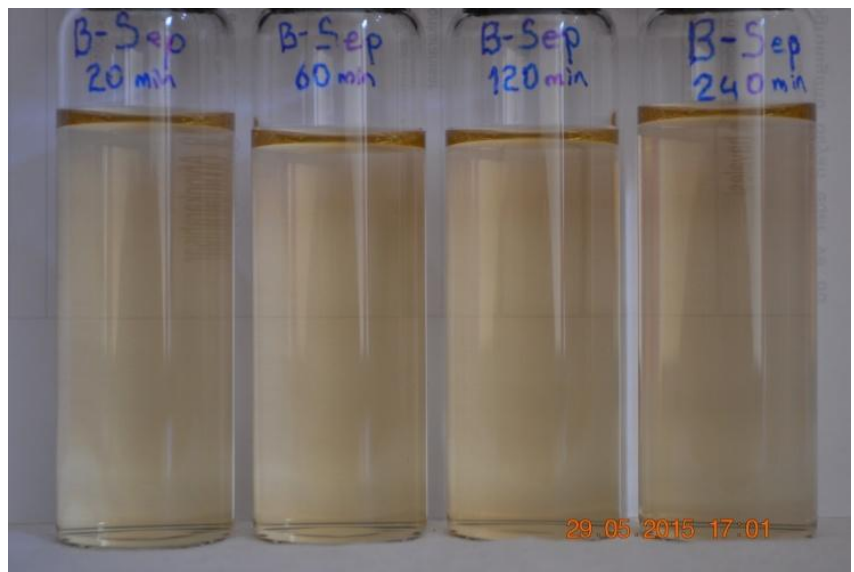

(a)

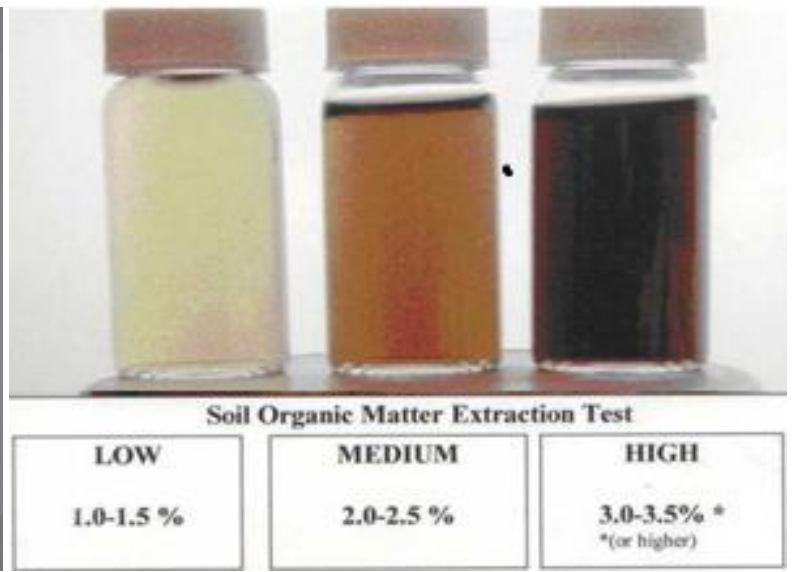

(b)

Fig. 8. Qualitative comparison of sepiolite organic matter (a) obtained in different extraction times with the reference organic matter (b) extraction test (UBC, 2015). 


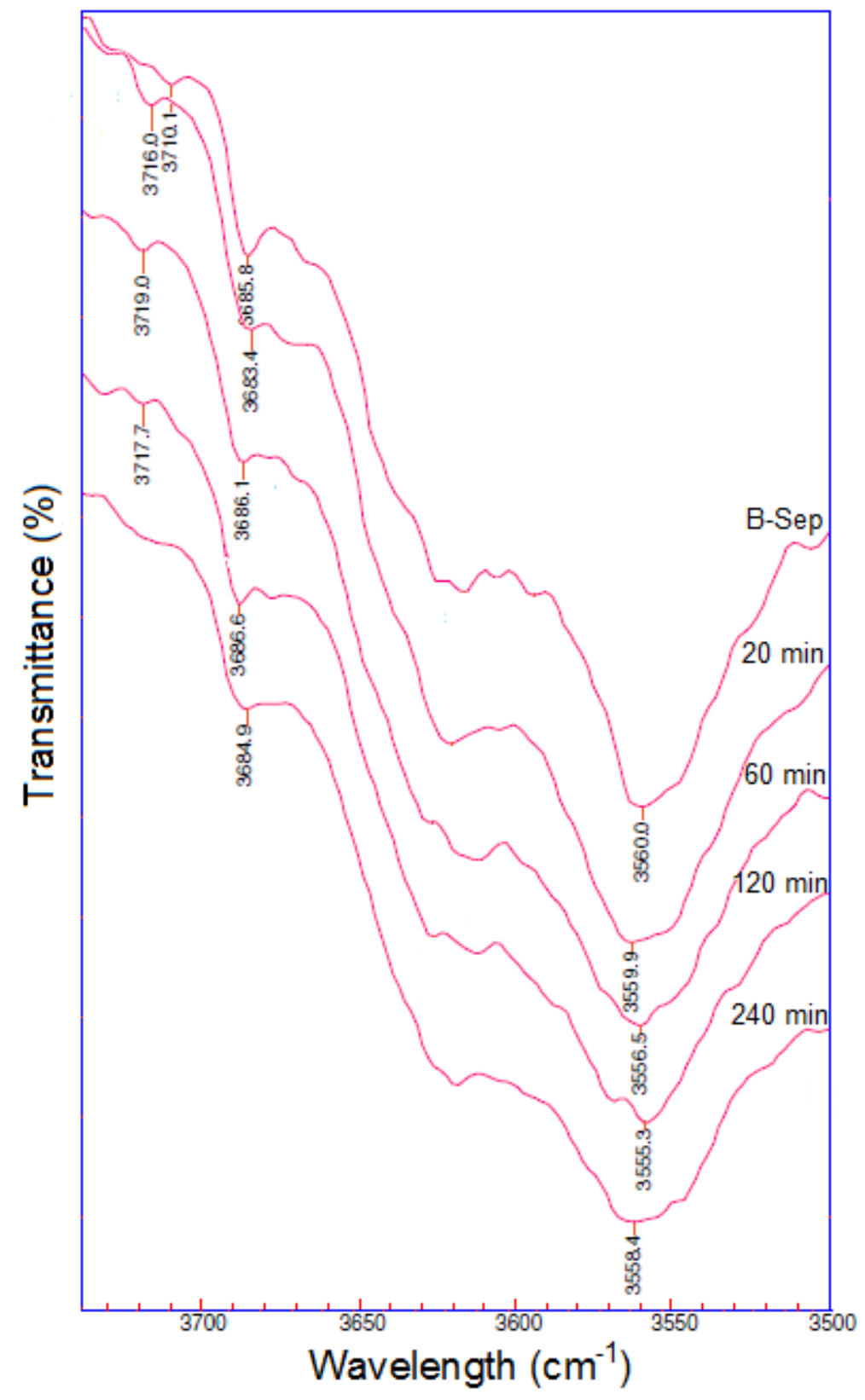

Fig. 9. FTIR specra of the raw and humic acid extracted sepiolite as a function of extraction time. 
(a) 21191 r 61137

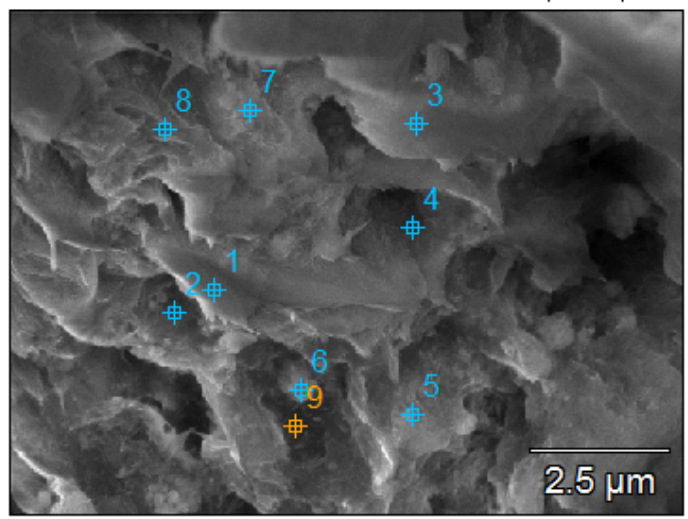

\begin{tabular}{lrrrrrr}
\hline B-Sep & \multicolumn{1}{c}{$\mathrm{O}$} & \multicolumn{1}{c}{$\mathrm{Si}$} & $\mathrm{Mg}$ & $\mathrm{Ca}$ & $\mathrm{Al}$ & $\mathrm{K}$ \\
\hline Pt-1 & 29.52 & 38.08 & 16.44 & 4.70 & 0.45 & 0.45 \\
\hline Pt-2 & 14.27 & 48.62 & 18.84 & 13.15 & 1.04 & 1.04 \\
\hline Pt-3 & 28.93 & 24.29 & 14.65 & 22.29 & 0.38 & 0.38 \\
\hline Pt-4 & 9.50 & 52.27 & 15.69 & 16.17 & 0.47 & 0.47 \\
\hline Pt-5 & 15.32 & 51.66 & 17.05 & 8.15 & 0.57 & 0.57 \\
\hline Pt-6 & 14.74 & 33.83 & 17.08 & 31.59 & 0.50 & 0.50 \\
\hline Pt-7 & 40.53 & 24.80 & 16.95 & 12.29 & 0.82 & 0.82 \\
\hline Pt-8 & 40.97 & 32.51 & 18.21 & 3.83 & 0.70 & 0.70 \\
\hline Pt-9 & 9.91 & 52.15 & 18.89 & 15.67 & 0.62 & 0.62 \\
\hline$\sum_{n=1}^{n}$ Pt/n & 22.63 & 39.80 & 17.09 & 14.20 & 0.62 & 0.62 \\
\hline
\end{tabular}

(b)

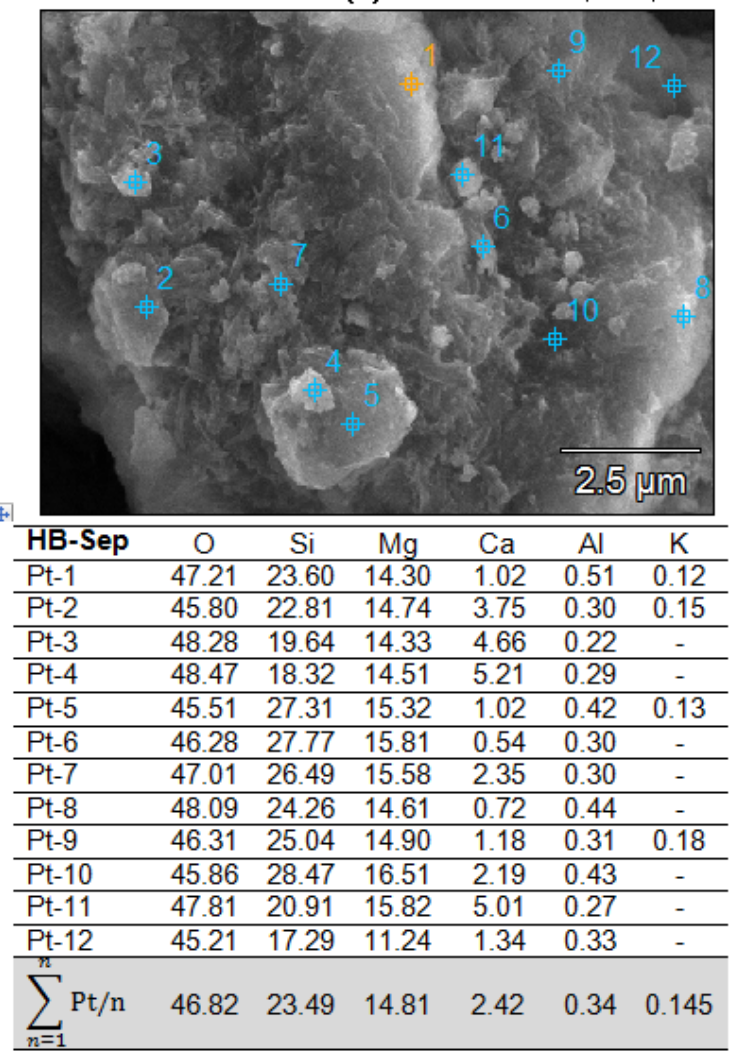

(c)

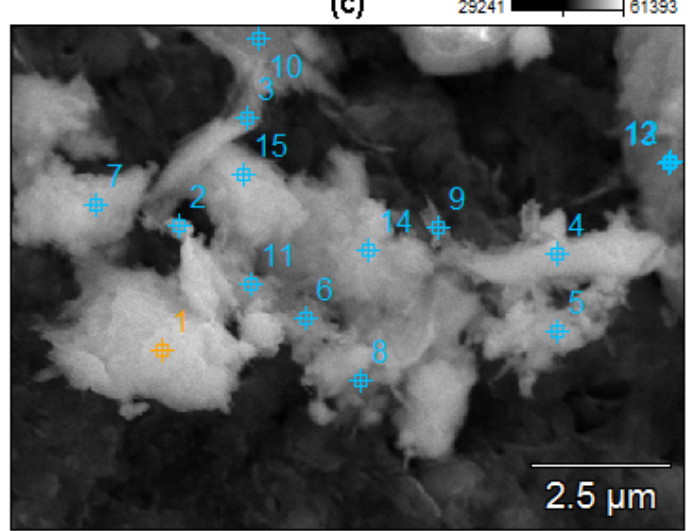

\begin{tabular}{lrrrrrr}
\hline HB-Sep & \multicolumn{1}{c}{$\mathrm{O}$} & \multicolumn{1}{c}{$\mathrm{Si}$} & $\mathrm{Mg}$ & $\mathrm{Ca}$ & $\mathrm{Al}$ & $\mathrm{K}$ \\
\hline $\mathrm{Pt}-1$ & 44.80 & 16.89 & 10.33 & 0.81 & 0.19 & - \\
\hline $\mathrm{Pt}-2$ & 32.29 & 7.58 & 6.00 & 2.23 & 0.12 & - \\
\hline $\mathrm{Pt}-3$ & 36.03 & 11.06 & 6.77 & 0.82 & 0.10 & - \\
\hline $\mathrm{Pt}-4$ & 1.16 & 15.93 & 10.03 & 0.50 & 0.12 & - \\
\hline $\mathrm{Pt}-5$ & 39.23 & 12.72 & 7.54 & 2.13 & 0.19 & 0.18 \\
\hline $\mathrm{Pt}-6$ & 36.13 & 11.60 & 6.71 & 0.77 & 0.18 & - \\
\hline $\mathrm{Pt}-7$ & 41.16 & 14.56 & 9.33 & 1.13 & 0.20 & - \\
\hline $\mathrm{Pt}-8$ & 29.33 & 9.49 & 5.69 & 1.56 & 0.14 & - \\
\hline $\mathrm{Pt}-9$ & 24.20 & 5.51 & 3.45 & 0.52 & - & - \\
\hline $\mathrm{Pt}-10$ & 29.89 & 8.40 & 5.14 & 0.77 & 0.06 & - \\
\hline $\mathrm{Pt}-11$ & 38.81 & 12.94 & 7.58 & 0.41 & 0.14 & - \\
\hline $\mathrm{Pt}-12$ & 39.83 & 15.22 & 11.61 & 6.37 & 0.22 & - \\
\hline Pt-13 & 37.92 & 15.18 & 11.84 & 6.64 & 0.25 & - \\
\hline $\mathrm{Pt}-14$ & 42.68 & 15.97 & 10.35 & 1.43 & 0.21 & 0.10 \\
\hline $\mathrm{Pt}-15$ & 44.44 & 17.90 & 10.95 & 0.34 & 0.11 & - \\
\hline$\sum_{n=1}^{n} \mathrm{Pt} / \mathrm{n}$ & 34.53 & 12.73 & 8.22 & 1.76 & 0.16 & 0.14 \\
\hline
\end{tabular}

Fig. 10. SEM images and the semiquantitative EDAX analyses of the raw sepiolite (a) and HA-extracted sepiolite at $20 \mathrm{~min}(\mathrm{~b})$ and $240 \mathrm{~min}$ (b), respectively. 


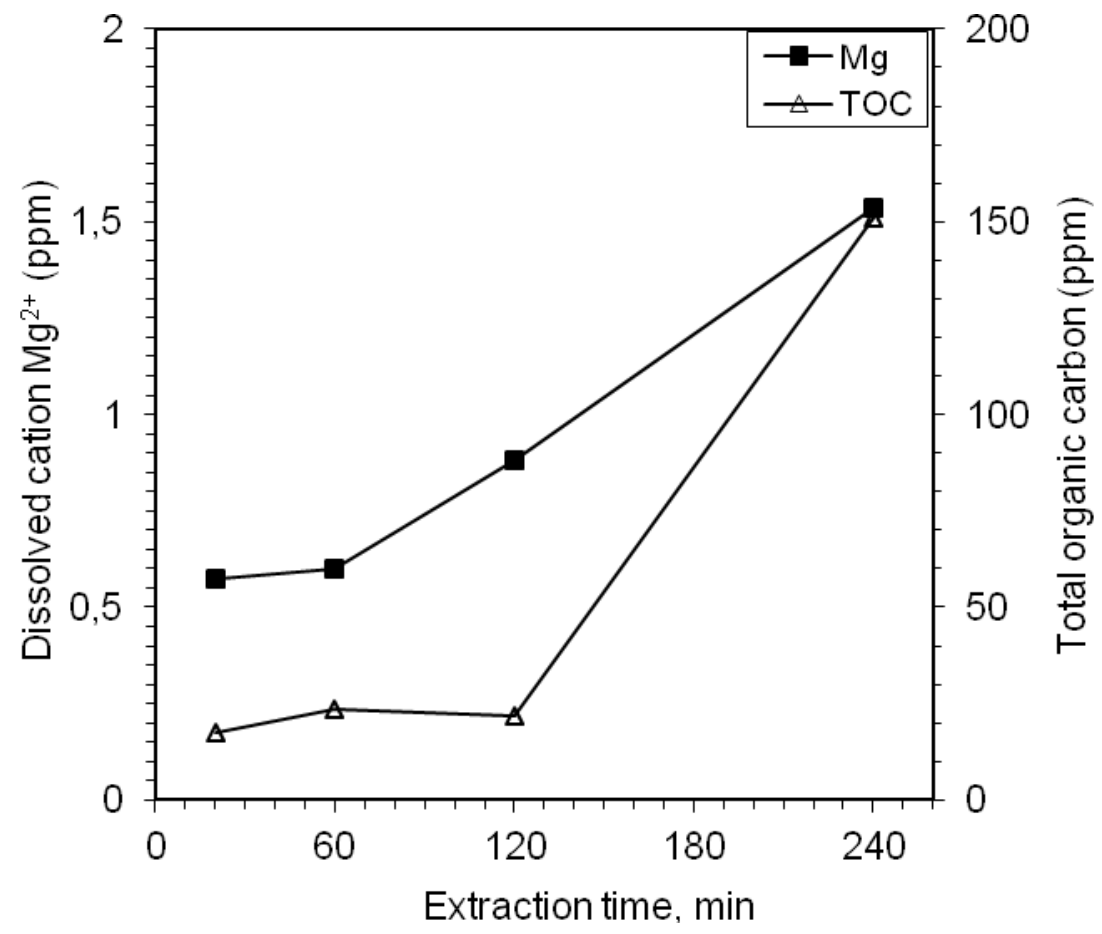

Fig. 11. Kinetic of $\mathrm{Mg}$ dissolution from sepiolite and released TOC as a function of extraction time $(\mathrm{pH}>11)$.

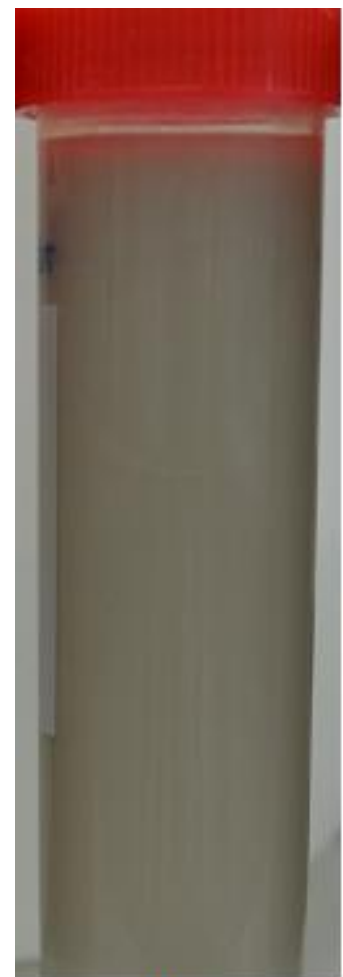

(a)

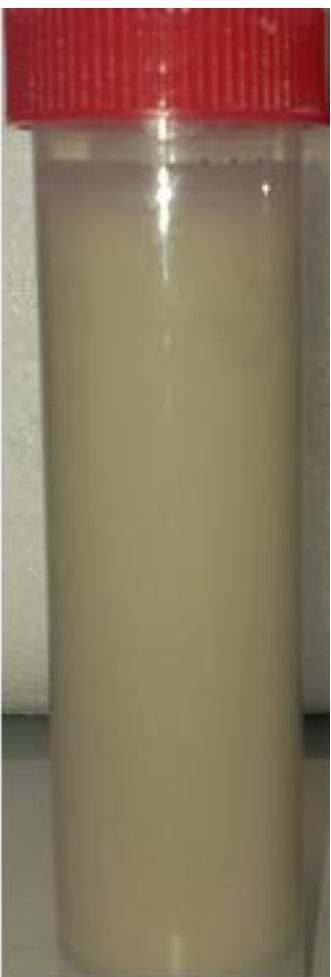

(b)

Fig. 12. HA extracted sepiolite suspension after 1 month (a) and 6 months (b) (Extraction time, $240 \mathrm{~min} ; \mathrm{pH}, 11.98)$. 